\title{
Physical and biogeochemical impacts of RCP8.5 scenario in the Peru upwelling system
}

\author{
Vincent Echevin ${ }^{1}$, Manon Gévaudan ${ }^{1,2,3}$, Dante Espinoza-Morriberón ${ }^{2}$, Jorge Tam ${ }^{2}$, Olivier Aumont ${ }^{1}$, \\ Dimitri Gutierrez ${ }^{2,4}$, and François Colas ${ }^{1,2}$ \\ ${ }^{1}$ Sorbonne Université, LOCEAN-IPSL, CNRS/IRD/MNHN, 4 place Jussieu, 75252 Paris, France \\ ${ }^{2}$ Instituto del Mar del Peru (IMARPE), Esquina General Gamarra y Valle, Callao, Peru \\ ${ }^{3}$ Laboratoire d'Etudes en Géophysique et Océanographie Spatiales, 14 av. E.Belin, 31400 Toulouse, France \\ ${ }^{4}$ Laboratorio de Ciencias del Mar, Universidad Peruana Cayetano Heredia, Lima, Peru
}

Correspondence: Vincent Echevin (vincent.echevin@ird.fr)

Received: 9 January 2020 - Discussion started: 20 January 2020

Revised: 6 May 2020 - Accepted: 15 May 2020 - Published: 1 July 2020

\begin{abstract}
The northern Humboldt Current system (NHCS or Peru upwelling system) sustains the world's largest small pelagic fishery. While a nearshore surface cooling has been observed off southern Peru in recent decades, there is still considerable debate on the impact of climate change on the regional ecosystem. This calls for more accurate regional climate projections of the 21 st century, using adapted tools such as regional eddy-resolving coupled biophysical models. In this study three coarse-grid Earth system models (ESMs) from the Coupled Model Intercomparison Project Phase 5 (CMIP5) are selected based on their biogeochemical biases upstream of the NHCS, and simulations for the RCP8.5 climate scenario are dynamically downscaled at $\sim 12 \mathrm{~km}$ resolution in the NHCS. The impact of regional climate change on temperature, coastal upwelling, nutrient content, deoxygenation, and the planktonic ecosystem is documented. We find that the downscaling approach allows us to correct major physical and biogeochemical biases of the ESMs. All regional simulations display a surface warming regardless of the coastal upwelling trends. Contrasted evolutions of the NHCS oxygen minimum zone and enhanced stratification of phytoplankton are found in the coastal region. Whereas trends of downscaled physical parameters are consistent with ESM trends, downscaled biogeochemical trends differ markedly. These results suggest that more realism of the ESM circulation, nutrient, and dissolved oxygen fields is needed in the eastern equatorial Pacific to gain robustness in the projection of regional trends in the NHCS.
\end{abstract}

\section{Introduction}

Eastern boundary upwelling systems (EBUSs) are oceanic systems where alongshore winds generate the upwelling of deep, cold, and nutrient-replete waters. This drives a high biological productivity and thriving small pelagic fisheries which are major sources of income for the adjacent countries. In particular, the Peruvian upwelling system (also known as the northern Humboldt Current system, NHCS in the following), located in the southeastern tropical Pacific, is the most productive EBUS in terms of fish catch (Chavez et al., 2008), due to its rich anchovy fishery. Moreover, the subsurface water masses in the NHCS are located in the poorly ventilated so-called "shadow zone" of the southeastern Pacific (Luyten et al., 1983). This low ventilation creates a subsurface water body with a very low oxygen concentration, the oxygen minimum zone (OMZ). The OMZ results from a balance between oxygen consumption by respiration of large amounts of organic matter exported from the highly productive surface layer and ventilation by the equatorial current system composed of eastward jets transporting relatively oxygenated waters (Czeschel et al., 2011; Montes et al., 2014). A particular aspect of the NHCS OMZ is its very low oxygen concentration (anoxia) at relatively shallow depths, which impacts the local marine ecosystem (Stramma et al., 2010; Bertrand et al., 2011).

In recent decades, public concern has risen about the impact of climate change on EBUSs. Using ship wind observations, Bakun (1990) showed that upwelling-favorable 
winds increased over recent decades (1950-1990) in several EBUSs. He proposed that nearshore winds would continue to intensify due to an enhanced differential heating between land and sea, driven by a stronger greenhouse effect over land. However, this hypothesis has been challenged in the NHCS because of observation bias (e.g., Tokinaga and Xie, 2011) and poleward displacement of the South Pacific anticyclone (Belmadani et al., 2013; Rykaczewski et al., 2015). Nevertheless, in situ and satellite sea surface temperatures (SSTs) have shown a conspicuous surface coastal cooling off southern Peru $\left(15^{\circ} \mathrm{S}\right)$ since the 1950s. This cooling, consistent with a wind increase found in the ERA40 reanalysis, suggests a possible intensification of the wind-driven upwelling (Gutierrez et al., 2011).

Recent analysis of the Coupled Model Intercomparison Project Phase 5 (CMIP5) global circulation models (GCMs) reported that the intensification of nearshore winds under scenarios of carbon dioxide concentration increase is mainly confined to the poleward portions of EBUS (Wang et al., 2015; Rykaczewski et al., 2015; Oyarzún and Brierley, 2019). However, the evolution of winds in the NHCS remains unclear (note that the NHCS stricto sensu was not included in these studies). Furthermore, the realism of IPCC GCMs is hampered by the coarse resolution of the model grids $(\sim 100-200 \mathrm{~km})$, which does not allow the representation of the details of coastal orography and coastline that influence the coastal wind structure.

A few downscaling studies focusing on regional wind changes in the NHCS have provided invaluable information. NHCS upwelling-favorable winds may weaken in the future, mainly during the productive austral summer season (Goubanova et al., 2011; Belmadani et al., 2014). However, only idealized extreme scenarios (preindustrial, doubling $\left(2 \times \mathrm{CO}_{2}\right)$, and quadrupling $\left(4 \times \mathrm{CO}_{2}\right)$ of carbon dioxide concentration) from a single GCM (IPSL-CM4; Marti et al., 2010) of the Intergovernmental Panel on Climate Change (IPCC) Fourth Assessment Report (AR4) were downscaled in these studies. In line with these studies, Echevin et al. (2012) used a regional ocean circulation model (RCM) forced by statistically downscaled atmospheric winds from Goubanova et al. (2011) to downscale the NHCS ocean temperature and circulation changes under $2 \times \mathrm{CO}_{2}$ and $4 \times \mathrm{CO}_{2}$ scenarios. They found a strong warming in the surface layer, of up to $\sim+5^{\circ} \mathrm{C}$ nearshore in the $4 \times \mathrm{CO}_{2}$ scenario with respect to preindustrial conditions, and an upwelling decrease during austral summer. Following the same regional modeling approach and using the downscaled winds from Belmadani et al. (2014), Oerder et al. (2015) found a year-round reduction in upwelling intensity, mitigated by an onshore geostrophic flow. The shoaling of upwelling source waters in the two scenarios suggests that upwelled waters could become less nutrient-rich and thereby reduce nearshore primary productivity (Brochier et al., 2013).
The impact of climate change on the NHCS productivity, oxygenation, and acidification has been even less investigated. Assuming the hypothesis of Bakun (1990) of increasing coastal winds, Mogollón and Calil (2018) found a moderate increase $(5 \%)$ the NHCS productivity using a RCM. However, they did not take into account the large-scale stratification changes driven by climate change that may significantly contribute to nearshore stratification and mitigate the upwelling (Echevin et al., 2012; Oerder et al., 2015). Following a similar approach, Franco et al. (2018) found a sustained acidification of NHCS shelf and slope waters under the Representative Concentration Pathway 8.5 scenario (RCP8.5, the so-called worst-case AR5 climate scenario corresponding to a $8.5 \mathrm{~W} \mathrm{~m}^{-2}$ heat flux driven by the greenhouse effect; e.g., van Vuuren et al., 2011), driven by changes in surface fluxes of atmospheric $\mathrm{CO}_{2}$ concentration and subsurface dissolved inorganic carbon concentrations. However, as in Mogollón and Calil (2018), the impact of climate change on NHCS surface winds, circulation, and stratification was unaccounted for in Franco et al. (2018).

In brief, previous regional modeling experiments were either obtained from (i) the downscaling of one single GCM or Earth system model (a GCM including a biogeochemical model, hereafter ESM), (ii) the analysis of relatively short time periods (e.g., 30 years in the stabilized phase of the $2 \times \mathrm{CO}_{2}$ and $4 \times \mathrm{CO}_{2}$ scenarios in Echevin et al., 2012; Oerder et al., 2015; Brochier et al., 2013), or (iii) simplified approaches that did not account for all physical forcings (e.g., Mogollón and Calil, 2018; Franco et al., 2018). More work is thus needed to evaluate the robustness of these findings under climate scenarios taking into account economic and population growth assumptions (e.g., RCP8.5) and over longer time periods (e.g., 100 years).

In the present work, three different ESMs are dynamically downscaled in the NHCS using a regional coupled dynamical-biogeochemical model. The studied time period is 2005-2100 under the RCP8.5 scenario. The regional trends from RCMs are compared to illustrate the diversity of regional climate change impacts. RCM trends are also contrasted with those of the ESMs in order to highlight the impact of the downscaling process. In the next section (Sect. 2) the regional model, the selection process of ESMs, and the downscaling methodology are described. Results are presented in Sect. 3: we describe the trends of key physical and biogeochemical parameters such as temperature, coastal upwelling, thermocline depth, oxygenation, nitrate, and productivity. The approach and implications of our work are discussed in Sect. 4. The conclusions and perspectives are drawn in Sect. 5. 


\section{Methodology}

\subsection{Ocean model}

The Regional Ocean Modeling System (ROMS) was used to simulate the ocean dynamics. The ROMS AGRIF (version v3.1.1 is used in this study) resolves the primitive equations, which are based on the Boussinesq approximation and hydrostatic vertical momentum balance (Penven et al., 2006; Shchepetkin and McWilliams, 2009). A fourth-order centered advection scheme allows the generation of steep tracer and velocity gradients (Shchepetkin and McWilliams, 1998). For a complete description of the model numerical schemes, the reader can refer to Shchepetkin and McWilliams (2005).

The model domain spans over the coasts of south Ecuador and Peru from $5^{\circ} \mathrm{N}$ to $22^{\circ} \mathrm{S}$ and from 95 to $69^{\circ} \mathrm{W}$. It is close to the one used in Penven et al. (2005). The horizontal resolution is $1 / 9^{\circ}$, corresponding to $\sim 12 \mathrm{~km}$. The bottom topography from STRM30 (Becker et al., 2009) is interpolated on the grid and smoothed in order to reduce potential errors in the horizontal pressure gradient. The vertical grid has 32 sigma levels.

Wind speed, air temperature, humidity, ROMS SST are used to compute latent and sensible heat flux online using a bulk parameterization (Liu et al., 1979).

\subsection{Biogeochemical model}

ROMS is coupled to the Pelagic Interaction Scheme for Carbon and Ecosystem Studies (PISCES) biogeochemical model. PISCES simulates the marine biological productivity and the biogeochemical cycles of carbon and main nutrients (P, N, Si, Fe; Aumont et al., 2015) as well as dissolved oxygen (DO) (e.g., Resplandy et al., 2012; Espinoza-Morriberón et al., 2019). It has three nonliving compartments, which are the semi-labile dissolved organic matter, small sinking particles, and large sinking particles, and four living compartments represented by two size classes of phytoplankton (nanophytoplankton and diatoms) and two size classes of zooplankton (microzooplankton and mesozooplankton). The ROMS-PISCES coupled model has been used to study the climatological (Echevin et al., 2008), intraseasonal (Echevin et al., 2014), and interannual variability of the surface productivity (Espinoza-Morriberón et al., 2017) and oxygenation (Espinoza-Morriberón et al., 2019) in the NHCS. Detailed parameterizations of PISCES (version 2) are reported in Aumont et al. (2015). Note that we used an earlier version of the model (PISCESv0) in this study, as PISCESv2 had not been coupled to ROMS yet at the beginning of our study. Here we describe the following parameterizations of PISCESv0: (i) diatoms and nanophytoplankton growth, microzooplankton grazing and mortality, and mesozooplankton mortality depend on temperature $(T)$ and are proportional to $e^{a . T}$ with $a=0.064{ }^{\circ} \mathrm{C}^{-1}$; (ii) mesozooplankton grazing on nanophytoplankton and diatoms is proportional to $e^{b . T}$ with $b=0.076{ }^{\circ} \mathrm{C}^{-1}$. These differences, in particular the larger temperature-enhanced mesozooplankton grazing with respect to phytoplankton growth, can play an important role in the context of surface warming in the NHCS. Boyd et al. (1981) measured grazing of Peruvian copepods; however further laboratory experiments are needed at different temperatures to calibrate these rates.

\section{Selection of the Earth system models}

Three CMIP5 ESMs are selected for the regional downscaling. The selection process is based on the nutrients simulated by the ESMs and on the evaluation of biogeochemical bias. Only five ESMs (CNRM, GFDL, IPSL, CESM, and Nor-ESM) represent the four nutrients (silicate, phosphate, nitrate, and iron) and DO required by PISCES. As different ESM versions were available, a total of eight ESMs (CNRM-CM5, GFDL-ESM2M, GFDLESM2G, IPSL-CM5A-MR, IPSL-CM5A-LR, IPSL-CM5BLR, CESM1, Nor-ESM1-ME) were compared to observations from the World Ocean Atlas (WOA2009, Fig. 1). Following Cabré et al. (2015), the ESM DO, nutrients, temperature, and salinity were averaged at $100^{\circ} \mathrm{W}$ between $5^{\circ} \mathrm{N}$ and $10^{\circ} \mathrm{S}$, near the location of the western open boundary of the RCM, for the period 1980-2005 (1950-2005 for $T$ and $S$ ). This meridional section intersects eastward jets: the equatorial undercurrent (EUC) at $0^{\circ} \mathrm{S}$ and the off-equatorial southern subsurface countercurrents (SSCCs) at $\sim 4$ and $\sim 8^{\circ} \mathrm{S}$ (Montes et al., 2010). These jets transport physical and biogeochemical properties to the Peru upwelling region (Montes et al., 2010, 2014; Oerder et al., 2015; Espinoza-Morriberón et al., 2017, 2019).

Visual examination of the ESM temperature and salinity profiles (Fig. 1) suggests that the corresponding biases are weak in comparison with other variables. The comparison between the biases of different variables can be quantified by computing a bias normalized by the mean state, averaged between 0 and $500 \mathrm{~m}$ depth $(0-250 \mathrm{~m}$ for temperature and salinity; see Table 1). The ESM normalized temperature bias is weaker than the biogeochemical biases (Table 1).

All ESMs simulate an oxygen decrease with depth (Fig. 1a), but oxygen values are too low (i.e., $<10 \mu \mathrm{mol} \mathrm{L}^{-1}$ ) in CESM1-BGC, GFDL-ESM2M, GFDL-ESM2G, and NorESM1-ME. Slightly negative values are attained below $300 \mathrm{~m}$ depth for GFDL-ESM2G. CNRM-CM5. In contrast, the three IPSL model versions, which all include PISCES as a biogeochemical component, overestimate the oxygen content above $\sim 600 \mathrm{~m}$ depth. Note that only CESM1-BGC is able to reproduce the observed oxygen increase below $400 \mathrm{~m}$ depth, which corresponds to the lower limit of the OMZ.

In terms of nitrate concentration, the most realistic models in the upper $300 \mathrm{~m}$ are GFDL-ESM2G, GFDL-ESM2M, and CESM1-BGC (Fig. 1b). However, the model biases become negative and increase strongly at depths greater than 
(a) ESM - oxygen concentration $100^{\circ} \mathrm{W}, 5^{\circ} \mathrm{N}-10^{\circ} \mathrm{S}$

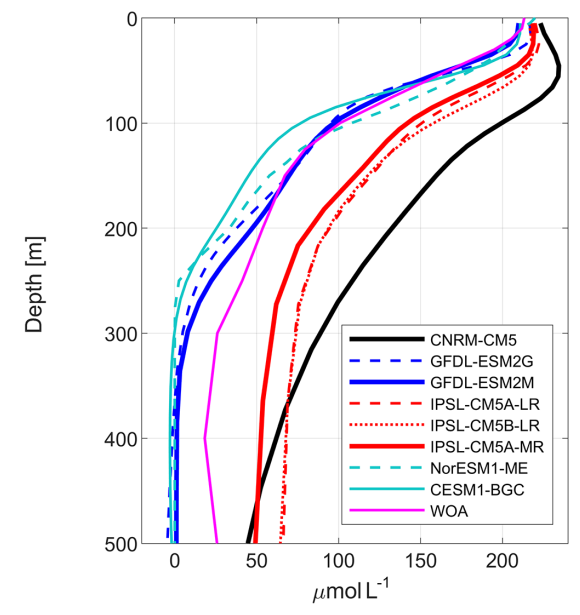

(c)

ESM - phosphate concentration $100^{\circ} \mathrm{W}, 5^{\circ} \mathrm{N}-10^{\circ} \mathrm{S}$

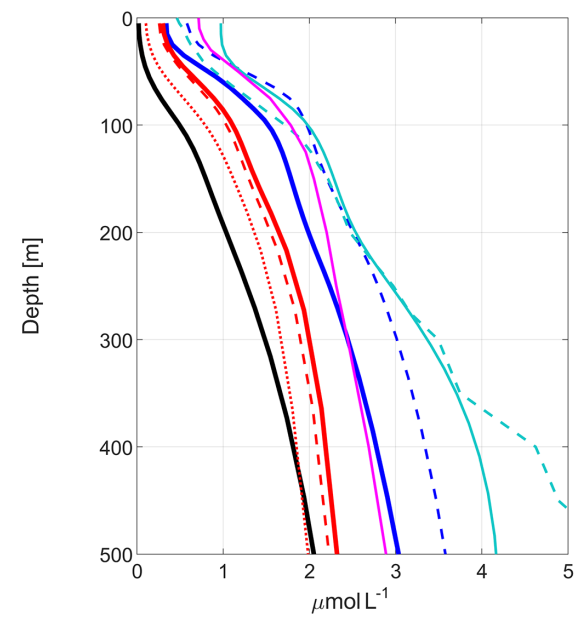

(e)

ESM - temperature $100^{\circ} \mathrm{W}, 5^{\circ} \mathrm{N}-10^{\circ} \mathrm{S}$

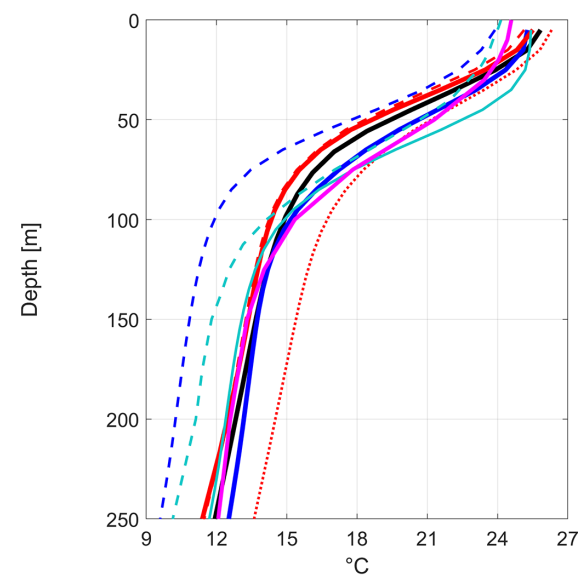

(b) ESM - nitrate concentration $100^{\circ} \mathrm{W}, 5^{\circ} \mathrm{N}-10^{\circ} \mathrm{S}$

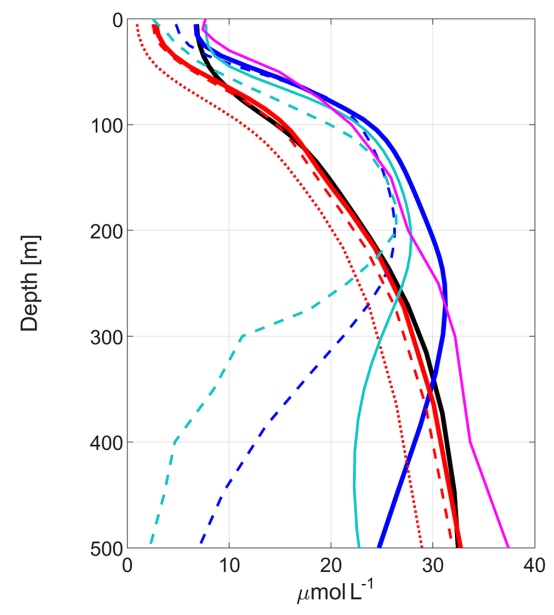

(d)

ESM - silicate concentration $100^{\circ} \mathrm{W}, 5^{\circ} \mathrm{N}-10^{\circ} \mathrm{S}$

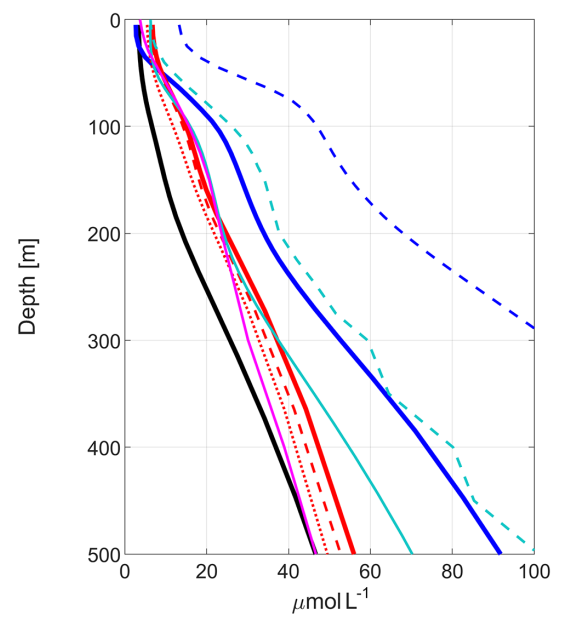

(f)

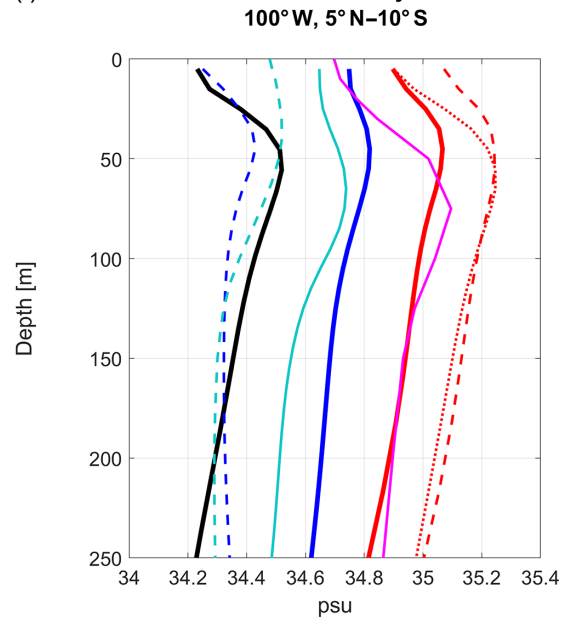

Figure 1. Vertical profiles of (a) oxygen, (b) nitrate, (c) phosphate, (d) silicate concentrations, (e) temperature, and (f) salinity in the eastern equatorial Pacific Ocean for eight Earth system models (ESMs: CNRM-CM5 (black line), GFDL-ESM2M (blue line), GFDL-ESM2G (blue dashed line), IPSL-CM5A-MR (red line), IPSL-CM5A-LR (red dashed line), IPSL-CM5B-LR (red dotted line), CESM1-BGC (cyan line), Nor-ESM1-ME (cyan dashed line)). All values are averaged along $100^{\circ} \mathrm{W}$ between $5^{\circ} \mathrm{N}$ and $10^{\circ} \mathrm{S}$. The three selected models are shown in thick colored lines. WOA observations are marked by magenta lines. ESM biogeochemical variables are averaged for the 1981-2005 period, while ESM temperature and salinity are averaged for the 1950-2005 period. 
Table 1. Normalized biases of the ESMs compared to WOA. They were calculated at each depth as $100 \times \frac{\left|X_{\text {model }}(z)-X_{\text {obs }}(z)\right|}{X_{\text {obs }}(z)}$ and then averaged over $500 \mathrm{~m}$ depth. Bold values indicate the downscaled ESMs.

\begin{tabular}{lrrrrrr}
\hline ESM & Temperature & Salinity & Oxygen & Nitrate & Silicate & Phosphate \\
\hline CESM1-BGC & $6 \%$ & $0.5 \%$ & $67 \%$ & $20 \%$ & $21 \%$ & $24 \%$ \\
IPSL-CM5A-LR & $13 \%$ & $0.3 \%$ & $133 \%$ & $24 \%$ & $12 \%$ & $30 \%$ \\
IPSL-CM5B-LR & $5 \%$ & $0.3 \%$ & $122 \%$ & $34 \%$ & $12 \%$ & $41 \%$ \\
IPSL-CM5-MR & $\mathbf{1 5 \%}$ & $\mathbf{0 . 5} \%$ & $\mathbf{8 3} \%$ & $\mathbf{2 0} \%$ & $\mathbf{1 6 \%}$ & $\mathbf{2 8} \%$ \\
CNRM-CM5 & $\mathbf{7 \%}$ & $\mathbf{2 . 1} \%$ & $\mathbf{1 5 0} \%$ & $\mathbf{1 7 \%}$ & $\mathbf{2 7 \%}$ & $\mathbf{5 2 \%}$ \\
GFDL-ESM2G & $25 \%$ & $2.1 \%$ & $60 \%$ & $33 \%$ & $220 \%$ & $19 \%$ \\
GFDL-ESM2M & $\mathbf{8 \%}$ & $\mathbf{1 . 2 \%}$ & $\mathbf{4 7 \%}$ & $\mathbf{1 1 \%}$ & $\mathbf{6 1 \%}$ & $\mathbf{9 \%}$ \\
NOR-ESM1 & $13 \%$ & $1.9 \%$ & $60 \%$ & $46 \%$ & $88 \%$ & $36 \%$ \\
\hline
\end{tabular}

$300 \mathrm{~m}$. A negative bias found in the three IPSL ESMs $(\sim 3-$ $4 \mu \mathrm{mol} \mathrm{L}{ }^{-1}$ for IPSL-CM5A-MR and IPSL-CM5A-LR and $\sim 6-8 \mu \mathrm{mol} \mathrm{L}{ }^{-1}$ for IPSL-CM5B-LR) is roughly constant over depth. CESM1-BGC, GFDL-ESM2G, and NorESM1ME display too low nitrate concentrations below $250 \mathrm{~m}$ depth, possibly due to denitrification in the anoxic OMZ (Fig. 1a).

The GFDL-ESM2M phosphate profile is very close to the observations (Fig. 1c, Table 1), whereas the three IPSL ESMs and CNRM-CM5 underestimate phosphate concentrations with a roughly constant bias over depth (negative bias of $\sim 0.5-1 \mu \mathrm{mol} \mathrm{L}^{-1}$ ). In contrast, NorESM1-ME, GFDLESM2G, and CESM1-BGC overestimate the phosphate concentrations.

The IPSL and CESM1-BGC silicate profiles are close to observations above $\sim 250 \mathrm{~m}$ depth, whereas the positive bias in GFDL-ESM2M and NorESM1-ME increases below $200 \mathrm{~m}$ depth. The CNRM-CM5 negative bias is moderate between 50 and $300 \mathrm{~m}$ depth (Fig. 1d).

To conclude, as the three IPSL ESMs and the CNRMCM5 include the PISCES biogeochemical model also used in the regional simulations and provide reasonable nutrient bias with respect to the other ESMs (Table 1), IPSL-CM5AMR (in which nitrate and phosphate bias are weaker than in the two other IPSL ESMs, Table 1) and CNRM-CM5 are selected. We also select GFDL-ESM2M, which represents the nitrate and phosphate profiles in the upper layers well, and whose bias did not increase at depth as in GFDL-EMS2G. CESM1-BGC also has weak biases with respect to the latter ESMs (Table 1), but some variables were not available from the archive (e.g., $10 \mathrm{~m}$ wind) at the beginning of this study. We thus restrict our study to the downscaling of three ESMs. The main characteristics of the selected ESM ocean models (grid spacing and biogeochemical structure) are summarized in Table 2. We refer to the ESMs as CNRM, IPSL, and GFDL in the following sections and figures.

\subsection{Atmospheric forcing methodology}

A bias correction is used to construct monthly forcing files (e.g., Oerder et al., 2015; note that daily files were not available for all ESMs). For each forcing variable $X$ (i.e., $X=$ wind velocity, air temperature, etc.), the biascorrected variable $X^{\prime}$ is computed as follows:

$X^{\prime}=X_{\mathrm{OBSclim}}+\left(X_{\mathrm{ESM}-\mathrm{RCP} 8.5}-X_{\mathrm{ESM}-\mathrm{hist}-\mathrm{clim}}\right)$.

$X_{\text {OBSclim }}$ corresponds to a monthly climatology of observed values, $X_{\mathrm{ESM}-\mathrm{RCP} 8.5}$ corresponds to the coarse-grid ESM values for each month, and $X_{\mathrm{ESM}}$-hist-clim corresponds to a monthly climatology of the coarse-grid ESM values during the historical period (2000-2010). This allows subtraction of the ESM mean bias, assuming that it remains identical over the historical period and over 2000-2100. This method has been used in several papers (Cambon et al., 2013; Echevin et al., 2012; Oerder et al., 2015). The SCOW (Risien and Chelton, 2008) surface wind and COADS (Da Silva et al., 1994) downward shortwave and longwave flux and air parameter (temperature and specific humidity) climatologies were used for $X_{\mathrm{OBSclim}}$. Note that submonthly wind variability may significantly impact surface chlorophyll in other EBUSs, such as off northern California where the wind variability is much stronger than off Peru (e.g., Gruber et al., 2006). Indeed, a previous regional modeling study in the NHCS showed a weak impact (less than $10 \%$ difference) of daily wind stress with respect to monthly wind stress on 7-year-averaged biogeochemical variables (Echevin et al., 2014). This suggests that using monthly winds may not significantly impact the climate trends reported in this study.

\subsection{Open boundary and initial conditions for physics and for biogeochemistry}

As in Echevin et al. (2012) and Oerder et al. (2015), the ESM monthly sea level, temperature, salinity, and horizontal velocity at the locations of the RCM open boundaries are directly interpolated on the model grid without bias correction. Given the important bias of the ESM mean biogeochemical state (e.g., Bopp et al., 2013; Cabré et al., 2015), we apply the 
Table 2. Characteristics of the ESMs selected for the regional downscaling. The values in parentheses indicate the thickness (in meters) of the surface layer in the ESM ocean model. Pg and Zg abbreviate "phytoplankton group" and "zooplankton group", respectively.

\begin{tabular}{llllll}
\hline $\begin{array}{l}\text { Earth system } \\
\text { model }\end{array}$ & $\begin{array}{l}\text { Ocean } \\
\text { model }\end{array}$ & $\begin{array}{l}\text { Biogeochemical } \\
\text { model }\end{array}$ & $\begin{array}{l}\text { Horizontal } \\
\text { resolution }\end{array}$ & $\begin{array}{l}\text { Number of } \\
\text { vertical levels }\end{array}$ & References \\
\hline IPSL-CM5A-MR & NEMOv3.2 & $\begin{array}{l}\text { PISCES }(2 \mathrm{Pg}, 2 \mathrm{Zg}, \\
\left.\mathrm{N}, \mathrm{P}, \mathrm{Si}, \mathrm{Fe}, \mathrm{O}_{2}\right)\end{array}$ & $\begin{array}{l}\Delta x=2^{\circ} \\
\Delta y=0.5-2^{\circ}\end{array}$ & $\begin{array}{l}31 \text { levels } \\
(10 \mathrm{~m})\end{array}$ & Dufresne et al. (2013) \\
\hline CNRM-CM5 & NEMOv3.2 & $\begin{array}{l}\text { PISCES }(2 \mathrm{Pg}, 2 \mathrm{Zg}, \\
\left.\mathrm{N}, \mathrm{P}, \mathrm{Si}, \mathrm{Fe}, \mathrm{O}_{2}\right)\end{array}$ & $\begin{array}{l}\Delta x=1^{\circ} \\
\Delta y=0.3-1^{\circ}\end{array}$ & $\begin{array}{l}42 \text { levels } \\
(10 \mathrm{~m})\end{array}$ & Voldoire et al. (2013) \\
\hline GFDL-ESM2M & MOM4p1 & TOPAZ2 (3 Pg, 3 Zg, & $\begin{array}{l}\Delta x=1^{\circ} \\
\Delta y=0.3-1^{\circ}\end{array}$ & $\begin{array}{l}50 \text { levels } \\
(10 \mathrm{~m})\end{array}$ & Dunne et al. (2012) \\
& & $\left.\mathrm{N}, \mathrm{P}, \mathrm{Si}, \mathrm{Fe}, \mathrm{O}_{2}\right)$ & $\Delta y=$ & & \\
\hline
\end{tabular}

bias correction described in Eq. (1): we add the WOA2009 $\left(1^{\circ} \times 1^{\circ}\right)$ monthly climatology of the biogeochemical variables (nitrate, silicate, phosphate, iron, dissolved inorganic carbon (DIC), dissolved organic carbon (DOC), alkalinity, oxygen) and the annual mean anomalies (see Eq. 1). The 3D fields were interpolated on the ROMS grid using the ROMSTOOLS package (Penven et al., 2008).

The three simulations are initialized as follows. Initial conditions from the ESM physical parameters of the historical simulation (2000-2010 January average) and WOA biogeochemical values (January) constitute the initial state. A 9year spinup simulation from 1997 to 2005 is then performed to reach equilibrium. The runs are then forced by RCP8.5 conditions until 2100. State variables and biogeochemical rates (e.g., primary production) are stored every $5 \mathrm{~d}$. The regional simulations are named R-IPSL, R-CNRM, and RGFDL in the following.

\subsection{Additional data sets}

Two ocean reanalysis products are used to evaluate the ESM equatorial circulation and thermocline in present conditions. The SODA 2.3.4 reanalysis (Carton and Giese, 2008) over the period 1992-2000 assimilates observational data in a general circulation model with an average horizontal resolution of $0.25^{\circ}$. The recently available GLORYS12V1 reanalysis over the period 1993-2017 is also used (Ferry et al., 2012). Altimeter data, in situ temperature and salinity vertical profiles, and satellite SST were jointly assimilated in GLORYS12V1 (Lellouche et al., 2018). This product is freely distributed by the Copernicus Marine Environment Monitoring Service.

Several sets of observations are used to evaluate the realism of ESMs and RCMs in present conditions (i.e., 20062015 period). In situ data include CARS2009 gridded fields of temperature, nitrate and oxygen $\left(0.5^{\circ} \times 0.5^{\circ}\right.$; Rigway et al., 2002), high-resolution $\left(0.1^{\circ} \times 0.1^{\circ}\right)$ regional monthly climatologies of temperature (Grados et al., 2018), and oxygen (Graco et al., 2020) including measurements collected during IMARPE (the Marine Institute of Peru) cruises. AVHRR satellite SST (2006-2015) is used to assess the RCM SST.
Surface chlorophyll $a$ monthly climatologies from SeaWiFS (1997-2010) and MODIS (2002-2015) are used to evaluate the RCM surface chlorophyll.

\subsection{Coastal indices}

Time series of coastal indices characterizing the variability over the central Peru shelf for specific variables are computed. The variables are averaged in a coastal band extending from the coastline to $100 \mathrm{~km}$ offshore and between 7 and $13^{\circ} \mathrm{S}$.

An index of coastal upwelling, the cross-shore transport in a coastal band, is computed from the model output (Colas et al., 2008; Oerder et al., 2015; Jacox et al., 2018). The mean horizontal transport is computed each month in a coastal strip extending from 7 to $13^{\circ} \mathrm{S}$ and from the coast to $100 \mathrm{~km}$ offshore. The transport is integrated vertically over the Ekman layer depth. The latter is diagnosed as follows: we compute the surface geostrophic current using model sea surface height, and we integrate the thermal wind relationship from the surface to the depth (equal to Ekman layer depth) at which the cross-shore current and the cross-shore geostrophic current differ by less than $10 \%$ (see Oerder et al., 2015, for more details). The computation of this index is more straightforward than one based on model vertical velocity (Jacox et al., 2018) and leads to similar values (e.g., see Fig. 4 in Jacox et al., 2018). In contrast with coastal upwelling indices based on Ekman transport only, this index takes into account the role of the cross-shore geostrophic current which can modulate the coastal upwelling (e.g., during El Niño events; Colas et al., 2008; Espinoza-Morriberón et al., 2017).

\subsection{Statistical methods}

Only timescales longer than 5-7 years (e.g., El Niño timescales) are studied in this work. Therefore the time series are low-pass filtered using a 10-year moving average. This allows us to filter the El Niño-Southern Oscillation (ENSO) variability, which is very strong in the NHCS but not the focus of the present study. Linear trends of the time series are 
Table 3. Differences (in percent) between 2100 and 2006 (with respect to values in 2006) computed from RCM and ESM linear trends and $R^{2}$ for wind stress, shortwave radiation, net longwave radiation, mixed-layer depth, coastal SST for RCM and $\mathrm{ESM}, 20^{\circ} \mathrm{C}$ isotherm depth at the coast for RCM and ESM and at $95^{\circ} \mathrm{W}$ for RCM, zonal velocity at $95^{\circ} \mathrm{W}$, and offshore and geostrophic fluxes. Bold font indicates significant values with a $90 \%$ level of confidence. Italic font indicates values below the $90 \%$ level of confidence.

\begin{tabular}{|c|c|c|c|c|c|c|c|}
\hline & $\begin{array}{l}\text { Wind } \\
\text { stress }\end{array}$ & $\begin{array}{r}\text { Shortwave } \\
\text { radiation }\end{array}$ & $\begin{array}{r}\text { Net longwave } \\
\text { radiation }\end{array}$ & $\begin{array}{r}\text { Downward } \\
\text { longwave } \\
\text { radiation }\end{array}$ & $\begin{array}{r}\text { Mixed-layer } \\
\text { depth }\end{array}$ & $\begin{array}{r}\text { Coastal } \\
\text { SST } \\
\text { (kelvin) }\end{array}$ & $\begin{array}{l}\text { ESM coastal } \\
\text { SST (kelvin) }\end{array}$ \\
\hline CNRM & $\begin{array}{r}-10.9 \pm 1.4 \% \\
R^{2}=0.65\end{array}$ & $\begin{array}{r}-6.8 \pm 0.3 \% \\
R^{2}=0.95\end{array}$ & $\begin{array}{r}37.8 \pm 1.2 \% \\
R^{2}=0.96\end{array}$ & $\begin{array}{r}10.0 \pm 0.4 \% \\
R^{2}=0.97\end{array}$ & $\begin{array}{r}\mathbf{1 8 . 5} \pm \mathbf{2 . 0} \% \\
R^{2}=0.73\end{array}$ & $\begin{array}{r}1.20 \pm 0.05 \% \\
R^{2}=0.95\end{array}$ & $\begin{array}{r}1.18 \pm 0.05 \% \\
R^{2}=0.95\end{array}$ \\
\hline GFDL & $\begin{array}{r}1.7 \pm 0.8 \% \\
R^{2}=0.13\end{array}$ & $\begin{array}{r}4.4 \pm 0.6 \% \\
R^{2}=0.66\end{array}$ & $\begin{array}{r}28.4 \pm 0.9 \% \\
R^{2}=0.97\end{array}$ & $\begin{array}{r}6.7 \pm 0.2 \% \\
R^{2}=0.98\end{array}$ & $\begin{array}{r}-16.2 \pm 1.1 \% \\
R^{2}=0.84\end{array}$ & $\begin{array}{r}0.67 \pm 0.03 \% \\
R^{2}=0.93\end{array}$ & $\begin{array}{r}0.78 \pm 0.02 \% \\
R^{2}=0.97\end{array}$ \\
\hline \multirow[t]{2}{*}{ IPSL } & $\begin{array}{r}-9.5 \pm 1.2 \% \\
R^{2}=0.67\end{array}$ & $\begin{array}{r}-0.5 \pm 0.2 \% \\
R^{2}=0.18\end{array}$ & $\begin{array}{r}21.1 \pm 0.8 \% \\
R^{2}=0.96\end{array}$ & $\begin{array}{r}9.8 \pm 0.4 \% \\
R^{2}=0.98\end{array}$ & $\begin{array}{r}-26.3 \pm 1.3 \% \\
R^{2}=0.91\end{array}$ & $\begin{array}{r}1.58 \pm 0.05 \% \\
R^{2}=0.97\end{array}$ & $\begin{array}{r}1.57 \pm 0.04 \% \\
R^{2}=0.98\end{array}$ \\
\hline & $\begin{array}{r}20^{\circ} \mathrm{C} \text { depth } \\
95^{\circ} \mathrm{W}\end{array}$ & $\begin{array}{r}20^{\circ} \mathrm{C} \text { depth } \\
\text { coast }\end{array}$ & $\begin{array}{l}\text { ESM } 20^{\circ} \mathrm{C} \\
\text { depth coast }\end{array}$ & $\begin{array}{r}\text { Velocity along } \\
\times \text { at } 95^{\circ} \mathrm{W}\end{array}$ & $\begin{array}{r}\text { Offshore } \\
\text { flux }\end{array}$ & $\begin{array}{r}\text { Geostrophic } \\
\text { flux }\end{array}$ & $\begin{array}{r}\text { Ekman } \\
\text { transport }\end{array}$ \\
\hline CNRM & $\begin{array}{r}25.7 \pm 3.1 \% \\
R^{2}=0.77\end{array}$ & $\begin{array}{r}101 \pm 16 \% \\
R^{2}=0.77\end{array}$ & $\begin{array}{r}101 \pm \mathbf{1 0 \%} \\
R^{2}=0.89\end{array}$ & $\begin{array}{r}-0.2 \pm 2.5 \% \\
R^{2}=0.00\end{array}$ & $\begin{array}{r}-22.8 \pm \mathbf{2 . 8 \%} \\
R^{2}=0.65\end{array}$ & $\begin{array}{r}3.0 \pm 4.2 \% \\
R^{2}=0.02\end{array}$ & $\begin{array}{r}11.7 \pm 1.2 \% \\
R^{2}=0.67\end{array}$ \\
\hline GFDL & $\begin{array}{r}5.2 \pm 1.4 \% \\
R^{2}=0.27\end{array}$ & $\begin{array}{r}11.5 \pm 7.2 \% \\
R^{2}=0.09\end{array}$ & $\begin{array}{r}20.9 \pm 3.9 \% \\
R^{2}=0.53\end{array}$ & $\begin{array}{r}-14.3 \pm 1.6 \% \\
R^{2}=0.64\end{array}$ & $\begin{array}{r}-0.5 \pm 2.8 \% \\
R^{2}=0.00\end{array}$ & $\begin{array}{r}-3.0 \pm 2.7 \% \\
R^{2}=0.03\end{array}$ & $\begin{array}{r}1.6 \pm 0.8 \% \\
R^{2}=0.09\end{array}$ \\
\hline IPSL & $\begin{array}{r}70.6 \pm 6.6 \% \\
R^{2}=0.91\end{array}$ & $\begin{array}{r}\mathbf{2 0 7} \pm \mathbf{5 1} \% \\
R^{2}=0.88\end{array}$ & $\begin{array}{r}126 \pm 12 \% \\
R^{2}=0.93\end{array}$ & $\begin{array}{r}-9.4 \pm 1.3 \% \\
R^{2}=0.58\end{array}$ & $\begin{array}{r}-25.1 \pm 1.6 \% \\
R^{2}=0.85\end{array}$ & $\begin{array}{r}0.3 \pm 2.3 \% \\
R^{2}=0.00\end{array}$ & $\begin{array}{r}-11.0 \pm 1.2 \% \\
R^{2}=0.70\end{array}$ \\
\hline
\end{tabular}

computed using a least-squares method. The percentage of change between 2006 and 2100 associated with the linear trends is listed in three tables (Table 3 for physical variables, Table 4 for oxygen and nitrate, and Table 5 for chlorophyll and zooplankton). Statistical significance is presented as a $90 \%$ confidence interval, based on a bootstrap method: we compute a 10000 -member synthetic distribution derived by randomly removing data in the annual series. The confidence limits of the trends are converted into confidence limits for the percentages reported in the tables.

\section{Results}

In the following sections we show that the RCM is able to represent the main characteristics of the NHCS coastal upwelling system thanks to its high spatial resolution (relative to the ESMs) and to the bias correction of the forcing. We then describe the long-term trends over the period 2006-2100 under the RCP8.5 scenario for key downscaled physical (surface and subsurface temperature, heat and momentum fluxes, upwelling) and biogeochemical parameters (oxygen and nutrient content, primary productivity, planktonic biomass) in the upwelling system but also in the equatorial band offshore of the NHCS. For selected variables we also compare the downscaled simulations and the coarse-grid ESMs. In the next section, we first characterize the downscaled physical fields.

\subsection{Physical mean state and variability}

\subsubsection{Sea surface temperature spatial patterns}

We first contrast the sea surface temperature (SST) patterns of the ESMs and RCMs to highlight the efficiency of the dynamical downscaling. The actual observed SST displays the cold water tongue along the coast and associated cross-shore SST gradient, characteristic of coastal upwelling (Fig. 2a). The RCM correctly simulates these upwelling features (Fig. 2b). The fine representation of the coastline, shelf and slope topography, and bias-corrected alongshore winds (see Sect. 2.4) plays a role in the correct representation of the upwelling structure. The upwelling vertical structure is also well reproduced in the RCMs. Mean cross-shore temperature profiles (within $500 \mathrm{~km}$ from the coast and between 7 and $13^{\circ} \mathrm{S}$ ) display the typical nearshore isotherms shoaling in the 0-100 m layer and deepening below, in good agreement with the CARS climatology (Fig. S1a-d in the Supplement).

In contrast, the ESM SST (CNRM is shown here as an example; similar results are found for IPSL and GFDL) in present conditions (2006-2015) displays a warm bias of 2$4{ }^{\circ} \mathrm{C}$ typical of ESMs (Flato et al., 2013) and no clear sign of coastal upwelling (Fig. 2c). In 2091-2100, the RCM displays a coastal upwelling of waters $\sim 2-3{ }^{\circ} \mathrm{C}$ warmer than in 2006-2015 (Fig. 2d). Again the ESM SST spatial pattern in 2091-2100 (Fig. 2e) resembles that of 2006-2015. Coastal upwelling is not present and a warming of $\sim 2-3^{\circ} \mathrm{C}$ is found over the main part of the domain. 
Table 4. Differences (in percent) between 2100 and 2006 (with respect to value in 2006) computed from RCM and ESM linear trends and $R^{2}$ for nearshore oxygen content, eastward oxygen flux, oxycline depth for RCM and ESM, nitrate content nearshore and at $95^{\circ} \mathrm{W}$, eastward nitrate flux, upward nitrate flux into the euphotic layer, and nitracline depth for RCM and ESM. Bold font indicates significant values with a $90 \%$ level of confidence. Italic font indicates values below the $90 \%$ level of confidence.

\begin{tabular}{|c|c|c|c|c|c|c|}
\hline & \multicolumn{6}{|c|}{ Oxygen } \\
\hline & $\begin{array}{r}\text { Coast } \\
100-200 \mathrm{~m}\end{array}$ & $\begin{array}{r}\text { Coast } \\
200-400 \mathrm{~m}\end{array}$ & $\begin{array}{r}\text { Flux } 95^{\circ} \mathrm{W} \\
50-200 \mathrm{~m}\end{array}$ & $\begin{array}{r}\text { Oxycline } \\
22 \mu \mathrm{mol} \mathrm{L}^{-1}\end{array}$ & $\begin{array}{r}\text { Oxycline } \\
44 \mu \mathrm{mol} \mathrm{L}^{-1}\end{array}$ & $\begin{array}{r}\text { Oxycline } \\
\text { ESM }\end{array}$ \\
\hline CNRM & $\begin{array}{r}483 \pm 110 \% \\
R^{2}=0.96\end{array}$ & $\begin{array}{r}722 \pm 709 \% \\
R^{2}=0.92\end{array}$ & $\begin{array}{r}32.8 \pm 3.1 \% \\
R^{2}=0.80\end{array}$ & $\begin{array}{r}209 \pm 27 \% \\
R^{2}=0.93\end{array}$ & $\begin{array}{r}119 \pm 12 \% \\
R^{2}=0.91\end{array}$ & $\begin{array}{r}85.0 \pm 4.3 \% \\
R^{2}=0.96\end{array}$ \\
\hline GFDL & $\begin{array}{r}-4.1 \pm 5.3 \% \\
R^{2}=0.01\end{array}$ & $\begin{array}{r}-14.3 \pm 7.3 \% \\
R^{2}=0.06\end{array}$ & $\begin{array}{r}-4.7 \pm 2.0 \% \\
R^{2}=0.11\end{array}$ & $\begin{array}{r}-\mathbf{5 . 5} \pm \mathbf{3 . 4 \%} \\
R^{2}=0.05\end{array}$ & $\begin{array}{r}-20.9 \pm 3.4 \% \\
R^{2}=0.44\end{array}$ & $\begin{array}{r}-9.1 \pm 2.4 \% \\
R^{2}=0.26\end{array}$ \\
\hline \multirow[t]{3}{*}{ IPSL } & $\begin{array}{r}-\mathbf{1 7 . 8} \pm \mathbf{2 . 5 \%} \\
R^{2}=0.41\end{array}$ & $\begin{array}{r}-48.2 \pm 2.0 \% \\
R^{2}=0.84\end{array}$ & $\begin{array}{r}-\mathbf{3 . 7} \pm \mathbf{0 . 8} \% \\
R^{2}=0.38\end{array}$ & $\begin{array}{r}-7.3 \pm 1.8 \% \\
R^{2}=0.23\end{array}$ & $\begin{array}{r}-\mathbf{4 . 5} \pm \mathbf{2 . 1 \%} \\
R^{2}=0.09\end{array}$ & $\begin{array}{r}13.2 \pm 1.6 \% \\
R^{2}=0.67\end{array}$ \\
\hline & \multicolumn{6}{|c|}{ Nitrate } \\
\hline & $\begin{array}{r}\text { Coast } \\
40-100 \mathrm{~m}\end{array}$ & $95^{\circ} \mathrm{W}$ & Flux $95^{\circ} \mathrm{W}$ & $\begin{array}{l}\text { Vertical flux coast } \\
\text { euphotic layer }\end{array}$ & Nitracline & $\begin{array}{r}\text { ESM } \\
\text { nitracline }\end{array}$ \\
\hline CNRM & $\begin{array}{r}-13.9 \pm 0.6 \% \\
R^{2}=0.94\end{array}$ & $\begin{array}{r}-\mathbf{1 8 . 3} \pm \mathbf{0 . 3 \%} \\
R^{2}=0.98\end{array}$ & $\begin{array}{r}-\mathbf{2 6 . 6} \pm \mathbf{1 . 3 \%} \\
R^{2}=0.91\end{array}$ & $\begin{array}{r}-23.7 \pm 1.1 \% \\
R^{2}=0.92\end{array}$ & $\begin{array}{l}\mathbf{8 2} \pm 13 \% \\
R^{2}=0.76\end{array}$ & $\begin{array}{r}96.8 \pm 4.5 \% \\
R^{2}=0.96\end{array}$ \\
\hline GFDL & $\begin{array}{r}-2.0 \pm 0.5 \% \\
R^{2}=0.31\end{array}$ & $\begin{array}{r}-\mathbf{5 . 1} \pm 0.3 \% \\
R^{2}=0.84\end{array}$ & $\begin{array}{r}-\mathbf{1 7 . 8} \pm \mathbf{1 . 6 \%} \\
R^{2}=0.69\end{array}$ & $\begin{array}{r}-0.5 \pm 1.2 \% \\
R^{2}=0.14\end{array}$ & $\begin{array}{r}-25.4 \pm 3.6 \% \\
R^{2}=0.51\end{array}$ & $\begin{array}{r}1.6 \pm 2.5 \% \\
R^{2}=0.01\end{array}$ \\
\hline IPSL & $\begin{array}{r}-10.4 \pm 0.3 \% \\
R^{2}=0.96\end{array}$ & $\begin{array}{r}-7.0 \pm 0.3 \% \\
R^{2}=0.92\end{array}$ & $\begin{array}{r}-20.3 \pm 1.1 \% \\
R^{2}=0.91\end{array}$ & $\begin{array}{r}-39.2 \pm 1.9 \% \\
R^{2}=0.89\end{array}$ & $\begin{array}{r}31.6 \pm 2.9 \% \\
R^{2}=0.78\end{array}$ & $\begin{array}{r}34.2 \pm 2.2 \% \\
R^{2}=0.90\end{array}$ \\
\hline
\end{tabular}

Table 5. Differences (in percent) between 2100 and 2006 (with respect to value in 2006) computed from RCM and ESM linear trends and $R^{2}$ for chlorophyll and zooplankton. Total chlorophyll and total zooplankton indicate depth-integrated values over $0-500 \mathrm{~m}$. Bold font indicates significant values with a $90 \%$ level of confidence. Italic font indicates values below the $90 \%$ level of confidence.

\begin{tabular}{|c|c|c|c|c|c|c|c|c|}
\hline & \multicolumn{2}{|c|}{ Surface chlorophyll } & \multicolumn{2}{|c|}{ Total chlorophyll } & \multicolumn{2}{|c|}{ Surface zooplankton } & \multicolumn{2}{|c|}{ Total zooplankton } \\
\hline & $\mathrm{RCM}$ & ESM & $\mathrm{RCM}$ & ESM & $\mathrm{RCM}$ & ESM & $\mathrm{RCM}$ & ESM \\
\hline CNRM & $\begin{array}{r}2.3 \pm 3.6 \% \\
R^{2}=0.02\end{array}$ & $\begin{array}{r}-104 \pm 4.9 \% \\
R^{2}=0.83\end{array}$ & $\begin{array}{r}-5.2 \pm 1.6 \% \\
R^{2}=0.28\end{array}$ & $\begin{array}{r}32.5 \pm 0.8 \% \\
R^{2}=0.96\end{array}$ & $\begin{array}{r}-1.4 \pm 1.6 \% \\
R^{2}=0.03\end{array}$ & $\begin{array}{r}-\mathbf{9 7 . 8} \pm \mathbf{3 . 8} \% \\
R^{2}=0.88\end{array}$ & $\begin{array}{r}-10.9 \pm 1.1 \% \\
R^{2}=0.78\end{array}$ & $\begin{array}{r}-\mathbf{5 5 . 5} \pm \mathbf{1 . 1} \% \\
R^{2}=0.96\end{array}$ \\
\hline GFDL & $\begin{array}{r}12.3 \pm 2.6 \% \\
R^{2}=0.48\end{array}$ & $\begin{array}{r}-10.9 \pm 0.9 \% \\
R^{2}=0.73\end{array}$ & $\begin{array}{r}3.1 \pm 0.9 \% \\
R^{2}=0.29\end{array}$ & $\begin{array}{r}-3.4 \pm 0.3 \% \\
R^{2}=0.72\end{array}$ & $\begin{array}{r}4.3 \pm 0.9 \% \\
R^{2}=0.44\end{array}$ & $\begin{array}{r}-15.3 \pm 0.7 \% \\
R^{2}=0.86\end{array}$ & $\begin{array}{r}-4.9 \pm 1.0 \% \\
R^{2}=0.48\end{array}$ & $\begin{array}{r}-7.4 \pm 0.4 \% \\
R^{2}=0.85\end{array}$ \\
\hline IPSL & $\begin{array}{r}17.0 \pm 1.8 \% \\
R^{2}=0.71\end{array}$ & $\begin{array}{r}-36.6 \pm 1.4 \% \\
R^{2}=0.94\end{array}$ & $\begin{array}{r}1.8 \pm 0.5 \% \\
R^{2}=0.15\end{array}$ & $\begin{array}{r}-3.4 \pm 0.2 \% \\
R^{2}=0.93\end{array}$ & $\begin{array}{r}-0.3 \pm 1.0 \% \\
R^{2}=0.00\end{array}$ & $\begin{array}{r}-\mathbf{3 3 . 0} \pm \mathbf{1 . 2 \%} \\
R^{2}=0.94\end{array}$ & $\begin{array}{r}-14.7 \pm 0.7 \% \\
R^{2}=0.92\end{array}$ & $\begin{array}{r}-11.1 \pm 0.4 \% \\
R^{2}=0.95\end{array}$ \\
\hline
\end{tabular}

\subsubsection{Trends of nearshore SST}

A steady warming of the surface coastal ocean is found in the three regional simulations (Fig. 3a). SST increases rapidly in R-IPSL starting in the $2020 \mathrm{~s}$, reaching $+4.5^{\circ} \mathrm{C}$ in 2100 , whereas it increases from the 2030s in the other simulations, reaching +3.5 and $+2{ }^{\circ} \mathrm{C}$ in R-CNRM and R-GFDL, respectively. Interestingly, decadal variability can produce decades during which the SST increase is stalled (a.k.a. "warming hiatus"), e.g., in 2035-2045 in R-CNRM and in 2040-2060 in R-GFDL. The ESM linear trends are very similar to the RCM nearshore warming trends (Fig. 3b, Table 3). Here the offset between the three ESM SST evolutions due to the different SST bias in 2005 (between 4 and $6{ }^{\circ} \mathrm{C}$ among the ESMs) has been corrected in order to better compare RCM and ESM trends. As an example, the spatial structures of the R-CNRM and CNRM SST anomalies are compared (Fig. 3c, d). The similarity between the two anomaly patterns is striking. Both display a maximum warming near the coasts and west of the Galápagos Islands where upwelling occurs. 
(a)

AVHRR - SST - 2006-2015

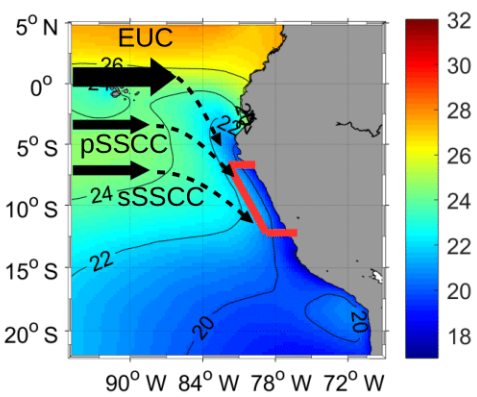

(d)

(b)

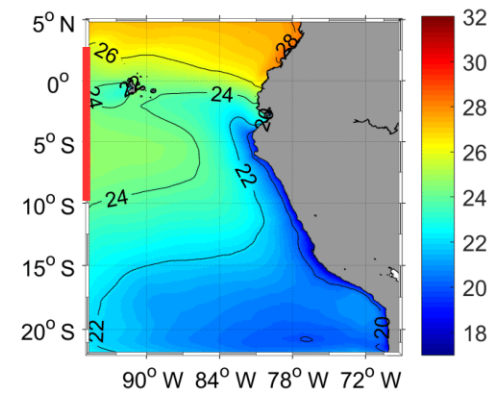

R-CNRM - SST - 2091-2100

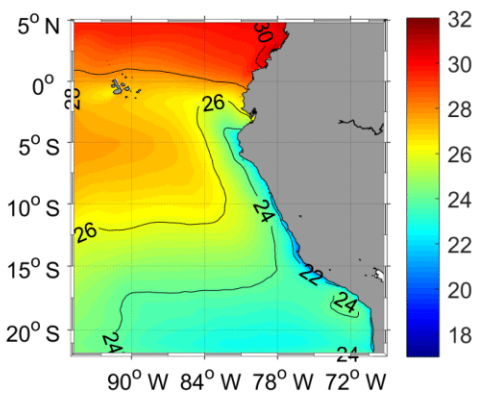

(c)

CNRM - SST - 2006-2015

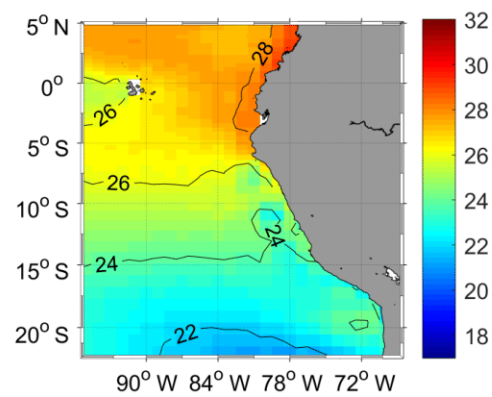

$(\mathrm{e})$

CNRM - SST - 2091-2100

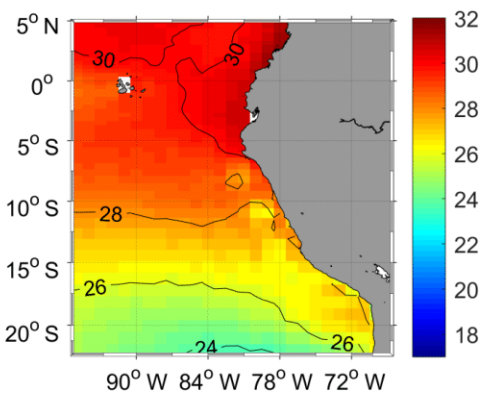

Figure 2. Annual mean SST $\left({ }^{\circ} \mathrm{C}\right.$ ) for (a) AVHRR surface observations (2006-2015), (b) R-CNRM (control period, 2006-2015), (c) CNRM (2006-2015), (d) R-CNRM (RCP8.5, 2091-2100), and (e) CNRM (RCP8.5, 2091-2100). The red box in (a) marks the coastal box in which surface and subsurface variables are averaged (see Methodology Sect. 2.8), and the red line in (b) marks the $95^{\circ} \mathrm{W}$ offshore section. Subsurface eastward equatorial currents (equatorial undercurrent (EUC) primary and secondary subsurface counter currents (pSSCC and sSSCC)) are sketched in (a).

\subsubsection{Temporal variability of heat and momentum fluxes}

As expected from greenhouse effect, downward longwave radiation from the ESMs increases steadily over the 21st century under RCP8.5 (Fig. 4a). The increase is stronger in IPSL $(+10 \%$; see Table 3$)$ and CNRM (10\%) than in GFDL (7 \%). This induces a decrease in the surface ocean cooling associated with net longwave radiation in the RCMs (Fig. 1d). Contrasted net downward shortwave radiation trends are simulated by the ESMs (Fig. 4b). Insolation decreases quasilinearly in CNRM $(-7 \%)$ and in GFDL $(-4 \%)$; however it is modulated by decadal variability in GFDL (note the slight insolation increase in 2090-2100). On the other hand, IPSL displays no trend $(0 \%)$. Furthermore, alongshore wind stress, the main driver of coastal upwelling, decreases in R-CNRM $(-11 \%)$ and R-IPSL $(-9 \%)$ in contrast with RGFDL $(+2 \%)$ (Fig. 4c). The wind stress decrease found in R-IPSL and R-CNRM is consistent with that found in CMIP3 simulations (Goubanova et al., 2010; Belmadani et al. 2013).

\subsubsection{Coastal upwelling}

Coastal upwelling (measured as the net offshore flux; see Sect. 2.7) decreases strongly in R-IPSL $(-23 \%)$ and RCNRM (-25\%) (Fig. 5a, Table 3). These downtrends are consistent with the wind stress downtrends (Fig. 4c) and mainly due to the Ekman transport contribution (Fig. 5c). In contrast, coastal upwelling remains stable in R-GFDL. The upwelling is modulated by decadal variability, whose amplitude can reach $5 \%-10 \%$ of the mean value. Decadal variability may generate decades of upwelling increase (e.g., 2090-2100 in R-CNRM), masking the long-term decrease. Upwelling decadal variability is mainly forced by variations in the onshore geostrophic transport, which on average compensates for $\sim 50 \%$ of the Ekman transport. As Ekman transport decreases over time in R-IPSL and RCNRM, the relative contribution of the geostrophic transport increases over time. This onshore current is driven by the higher sea level in the equatorial portion of the upwelling system than in its poleward portion (Colas et al., 2008; Oerder et al., 2015). This flow is occasionally remarkably strong (e.g., in 2090 in R-CNRM, 2035-2040 and 2065 in R-GFDL), whereas the trends are weak. 
(a)

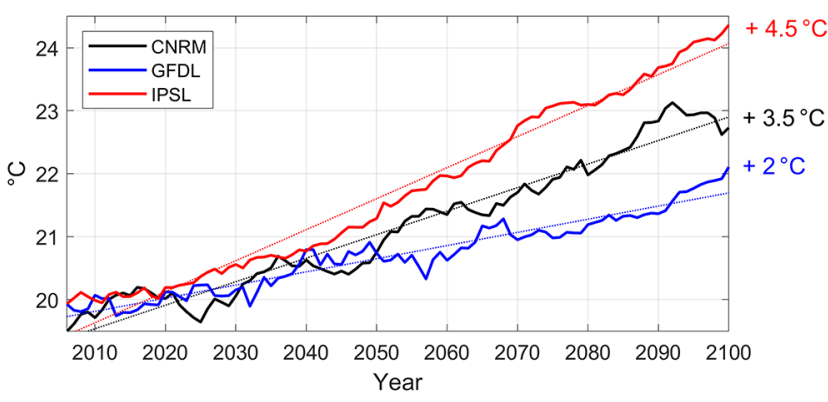

(c) RCM : CNRM-CM5 - SST anomalies (future - present)

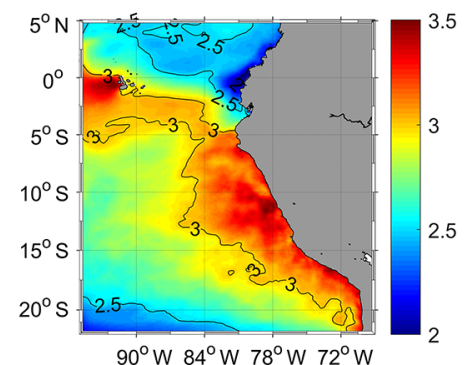

(b) ESM - SST - coastal $(0-100 \mathrm{~km})$

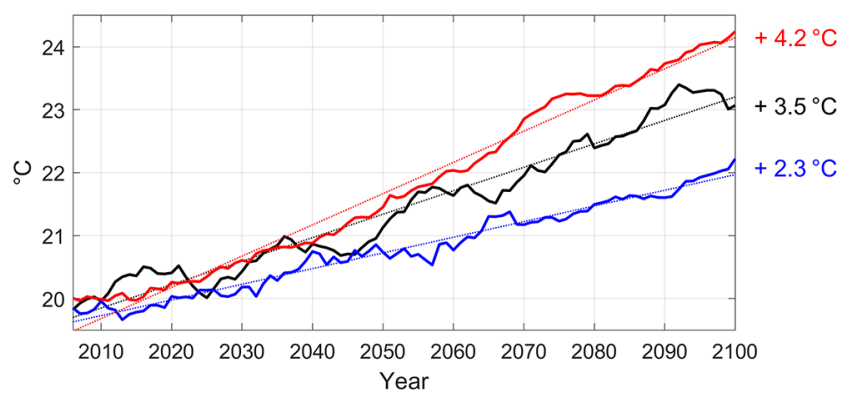

(d) ESM : CNRM-CM5 - SST anomalies (future - present)

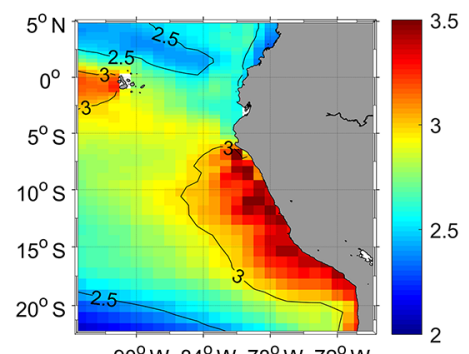

Figure 3. Coastal SST $\left({ }^{\circ} \mathrm{C}\right)$ in (a) the RCMs and (b) the ESMs (CNRM in black, GFDL in blue, IPSL in red). All fields are averaged in a coastal box (see Fig. 2a), and annual mean time series are filtered using a 10-year moving average. SST biases are removed from ESM, to compare with RCM (respectively 5, 6, and $4.5^{\circ} \mathrm{C}$ for CNRM, GFDL, and IPSL). Dotted lines indicate linear trends and percentage values indicate the change between 2006 and 2100 with respect to the present conditions using the linear trend values (i.e., $100 .(X(t=$ $2100)-X(t=2006)) / X(t=2006)$, where $X(t)$ is the linear trend). (c) R-CNRM SST anomaly (2091-2100 average minus 2006-2015) and (d) CNRM SST anomaly (2091-2100 average minus 2006-2015).

(a)

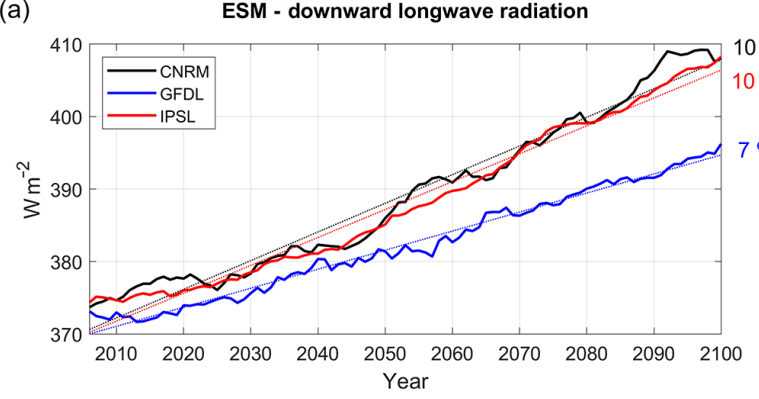

(c)

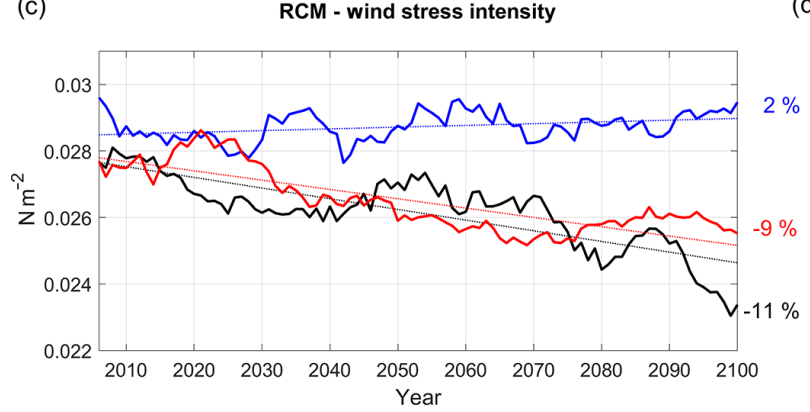

(b)

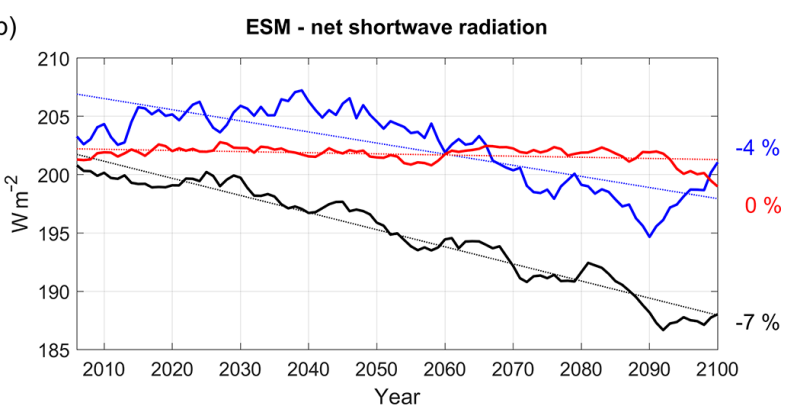

(d)

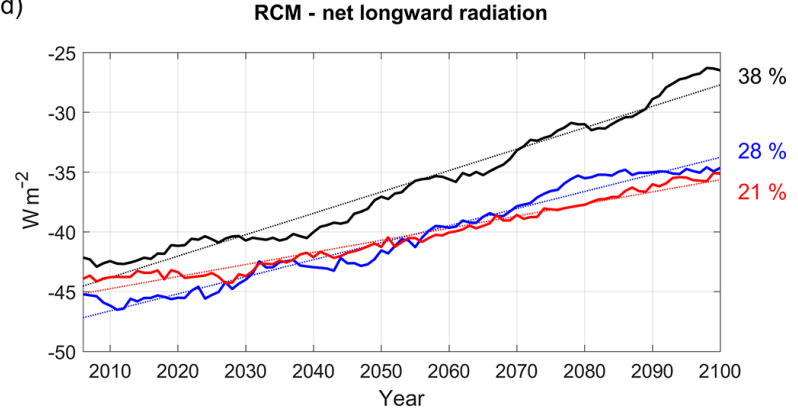

Figure 4. (a) ESM downward longwave radiation ( $\mathrm{W} \mathrm{m}^{-2}$, positive downward), (b) ESM net shortwave radiation ( $\mathrm{W} \mathrm{m}^{-2}$, positive downward), (c) RCM wind stress intensity $\left(\mathrm{N} \mathrm{m}^{-2}\right.$ ), and (d) RCM net longwave radiation ( $\mathrm{W} \mathrm{m}^{-2}$, positive downward), for the three RCMs (CNRM in black, GFDL in blue, IPSL in red). All fields are averaged in a coastal box (see Fig. 2a), and annual mean time series are filtered using a 10 -year moving average. 
(a)

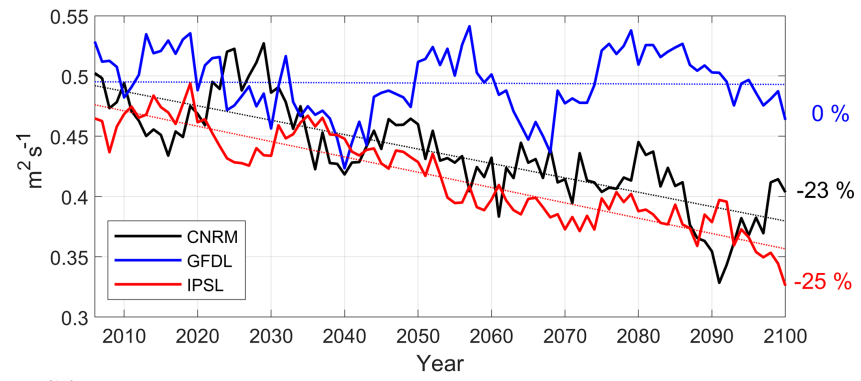

(b)

RCM - cross-shore geostrophic transport

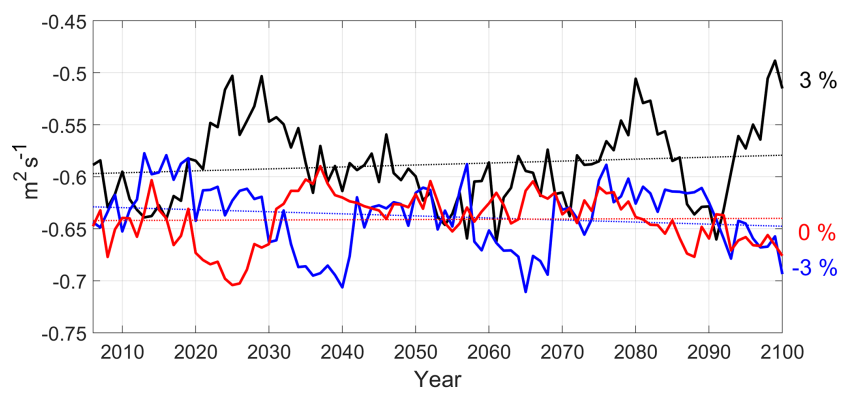

(c)

RCM - Ekman transport

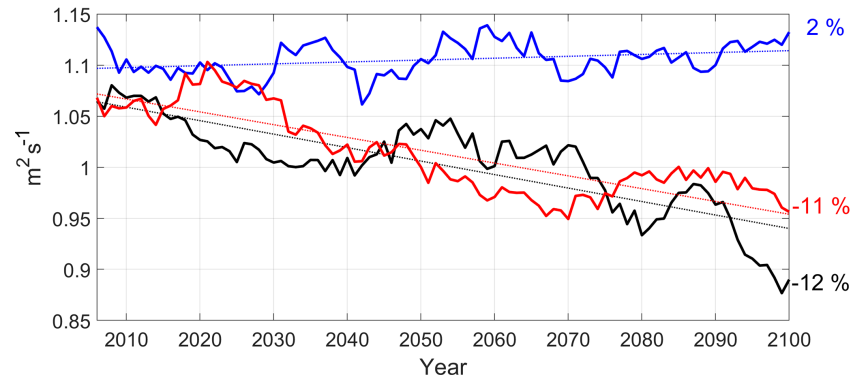

Figure 5. (a) Net offshore transport $\left(\mathrm{m}^{2} \mathrm{~s}^{-1}\right.$, positive offshore), vertically averaged in the Ekman layer, (b) cross-shore geostrophic transport compensating for the wind-driven upwelling $\left(\mathrm{m}^{2} \mathrm{~s}^{-1}\right)$ and (c) Ekman transport $\left(\mathrm{m}^{2} \mathrm{~s}^{-1}\right)$. All fields are averaged in a coastal box (see Fig. 2a) for the three RCMs (CNRM in black, GFDL in blue, IPSL in red). Annual mean time series are filtered using a 10year moving average.

\subsubsection{Subsurface temperature anomalies}

Nearshore subsurface temperature anomalies are impacted by equatorial subsurface temperature anomalies in two ways: thermocline anomalies may propagate along the equatorial and coastal wave guide (e.g., Echevin et al., 2011, 2014; Espinoza-Morriberón et al., 2017, 2018), and temperature anomalies may be transported eastward and poleward by the near-equatorial subsurface jets (Fig. 2a; Montes et al., 2010, 2011). The latter is particularly strong during eastern Pacific El Niño events (e.g., Colas et al., 2008, for the 1997-1998 event). The thermal structure of the upper layer is strongly impacted by climate change in the eastern equatorial Pacific. The depth of the $20^{\circ} \mathrm{C}$ isotherm (hereafter D20) is used to characterize the thickness of the warm surface layer. It in- (a)

RCM BC $-20^{\circ} \mathrm{C}$ isotherm depth - offshore $\left(95^{\circ} \mathrm{W}\right)$

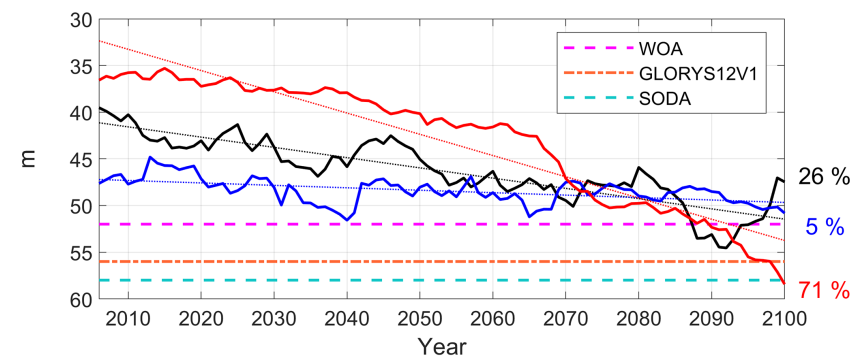

(b)

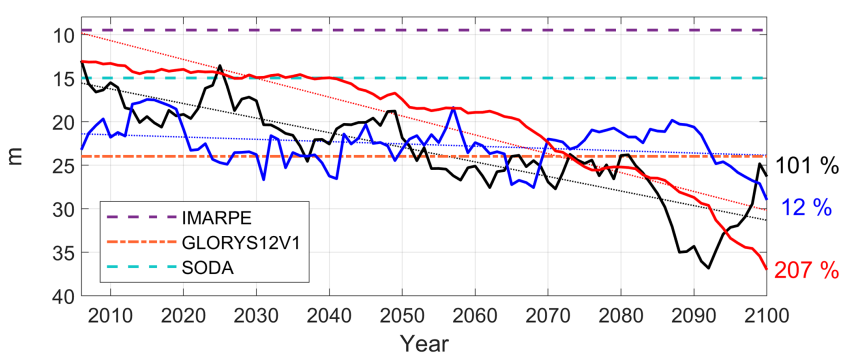

(c)

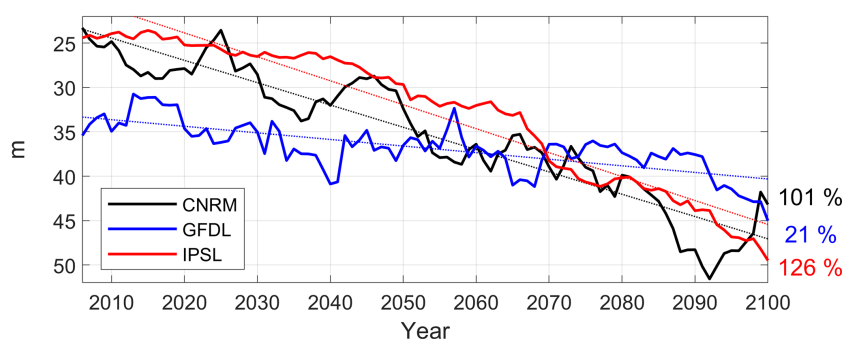

Figure 6. Depth of $20^{\circ} \mathrm{C}$ isotherm (D20, in meters) (a) at $95^{\circ} \mathrm{W}$, averaged between $2^{\circ} \mathrm{N}$ and $10^{\circ} \mathrm{S}$ (see red vertical line in Fig. 2b), (b) in the coastal box for the three RCMs and (c) for the three ESMs (CNRM in black, GFDL in blue, IPSL in red). The time series are filtered using a 10-year moving average. Climatological D20 from WOA (dashed magenta line) and two reanalyses (dashed-dotted orange line for GLORYS12V1 (1993-2017), dashed cyan line for SODA (1992-2000)) are also shown in (a). D20 from IMARPE climatology is marked by a dashed purple line in (b). Annual mean time series are filtered using a 10-year moving average.

creases in all ESMs, at different rates (Fig. 6a). The deepening is roughly linear in GFDL $(+5 \%$, Table 3$)$ and CNRM $(+26 \%)$. In contrast, it increases nonlinearly in IPSL, first by $\sim 1.5 \mathrm{~m}$ per decade between 2005 and 2065 and then by $\sim 5 \mathrm{~m}$ per decade between 2065 and 2100 . Note that D20 is shallower in the ESMs $(\sim 30-40 \mathrm{~m})$ than in observations $(\sim 52 \mathrm{~m}$ in WOA $)$ and in two ocean reanalyses $(\sim 56 \mathrm{~m}$ in GLORYS2V1 and $-58 \mathrm{~m}$ in SODA). A shallow thermocline is likely to be more impacted by greenhouse-induced surface warming in the model simulations than in the real ocean.

D20 coastal trends in the RCMs (Fig. 6b) are roughly similar to the offshore ESM equatorial trends. The coastal deep- 


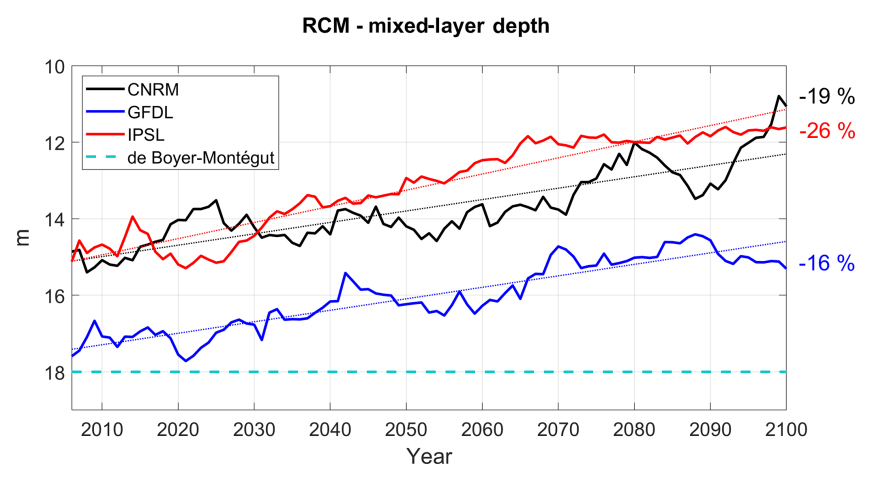

Figure 7. RCM mixed-layer depth (in meters) in the RCMs (CNRM in black, GFDL in blue, IPSL in red). Annual mean time series are filtered using a 10-year moving average. The climatological value derived from the De Boyer Montégut et al. (2004) climatology is marked by a dashed cyan line.

ening is moderate in R-GFDL (+12\%, Table 3$)$. In contrast, a strong linear deepening is found in R-CNRM $(+101 \%)$. As in the equatorial region, the D20 deepening is nonlinear in RIPSL, and the thickness of the warm surface layer more than doubles $(+207 \%)$. The RCM D20 values at the beginning of the century are within the range of estimated values from observations and reanalyses whereas D20 is slightly too deep in the ESMs (Fig. 6c), which highlights the dynamical downscaling ability to reduce part of this systematic bias. The RCM trends are roughly in line with the ESM coastal trends. D20 deepening can be amplified (e.g., $207 \%$ in R-IPSL vs. $126 \%$ in IPSL) or mitigated ( $12 \%$ in R-GFDL vs. $\sim 21 \%$ in GFDL, Fig. 6c) depending on the model. Decadal variability from the equatorial region propagates to the coastal regions with little change.

We now investigate the evolution of the RCM mixed layer. The RCM surface boundary layer thickness (hbl), determined by comparing a bulk Richardson number to a critical value (K-profile parameterization, KPP; Large et al., 1994), is a good proxy of the model mixed layer (e.g., Li and FoxKemper, 2017). The R-GFDL mixed layer in 2006-2015 is in fairly good agreement with the mixed-layer depth (computed from temperature profiles) from the coarse $2^{\circ} \times 2^{\circ}$ gridded climatology of de Boyer Montegut et al. (2004), whereas RIPSL and R-CNRM values are $\sim 3 \mathrm{~m}$ shallower.

A shoaling of the mixed layer is found in all simulations (Fig. 7), in line with the surface heating (Fig. 4a, b) and reduced wind-driven mixing (Fig. 4c). The shoaling is slightly stronger in R-IPSL and R-GFDL than in R-CNRM, possibly due to the stronger surface warming in R-IPSL (Table 3).

The near-equatorial subsurface, coastal subsurface, and surface temperature linear trends of the RCMs and ESMs are compared in Fig. 8. Near-equatorial subsurface trends are weakest in GFDL and strongest in IPSL, which is consistent with the stronger D20 deepening in IPSL (Fig. 6a). A similar ranking from weakest (R-GFDL) to strongest warming

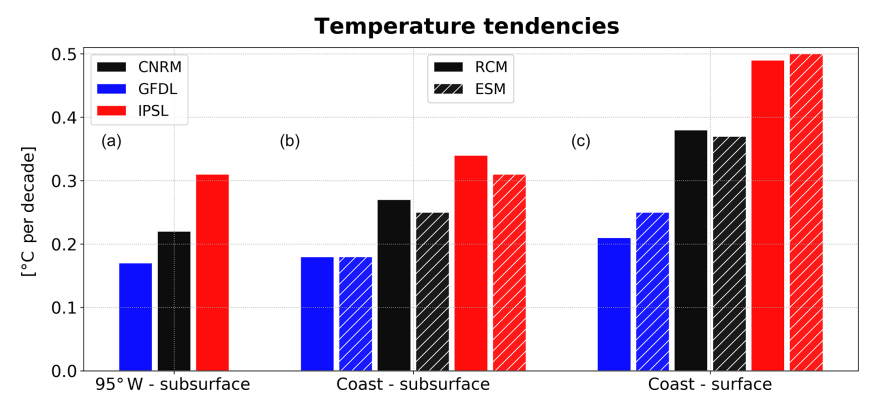

Figure 8. Depth-averaged RCM and ESM temperature linear trends between 2006 and $2100\left({ }^{\circ} \mathrm{C}\right.$ per decade) in the equatorial region $\left(95^{\circ} \mathrm{W}, 2^{\circ} \mathrm{N}-10^{\circ} \mathrm{S}, 50-200 \mathrm{~m}, \mathbf{a}\right)$, in the coastal region (b), and in the surface layer $(0-5 \mathrm{~m}, \mathbf{c})$. CNRM, GFDL, and IPSL trends are shown in black, blue, and red, respectively, and ESM trends are shown with hatching.

(R-IPSL) is found for the coastal subsurface warming and coastal surface warming. The equatorial water masses are transported towards the coasts (Montes et al., 2010; Oerder et al., 2015) and the subsurface layer trends increase by $6 \%$ in R-GFDL, $23 \%$ in R-CNRM, and $10 \%$ in R-IPSL with respect to the near-equatorial trends. The ESM trends are close to the RCM trends, which suggests that the nearshore subsurface warming is dominated by the eastward transport of warm near-equatorial subsurface waters in both the ESMs and RCMs. In the coastal region, the upper part of the 50$200 \mathrm{~m}$ subsurface water volume is upwelled into the mixed layer where additional heat is deposited by the local atmospheric fluxes (Fig. 4a, b).The coastal SST trends increase with respect to the coastal subsurface anomalies $(+17 \%$ in R-GFDL, $+37 \%$ in R-CNRM, $+44 \%$ in R-IPSL), underlining the impact of different local heat fluxes. The amplitude of the ESM SST trend is very close $(<10 \%$ change) to that of the RCM for R-IPSL and R-CNRM, which is consistent with the spatial patterns of SST change shown in Fig. 3c, d. Interestingly, the R-GFDL SST increase is $\sim 20 \%$ weaker than that of GFDL.

\subsection{Biogeochemical response of the NHCS under the RCP8.5 scenario}

We now investigate the impacts of regional climate change on the main biogeochemical characteristics of the NHCS, namely oxygenation, nutrients, and productivity.

\subsubsection{OMZ trends in response to the equatorial circulation}

The suboxic $\left(\mathrm{O}_{2}<5 \mu \mathrm{mol} \mathrm{L}{ }^{-1}\right.$; Karstensen et al., 2008) subsurface waters found in the NHCS result from a subtle balance between the eastward and poleward transport of relatively oxygenated waters from the equatorial region into the upwelling region, the ventilation due to mesoscale circulation (Thomsen et al., 2016; Espinoza-Morriberón et al., 
(a)

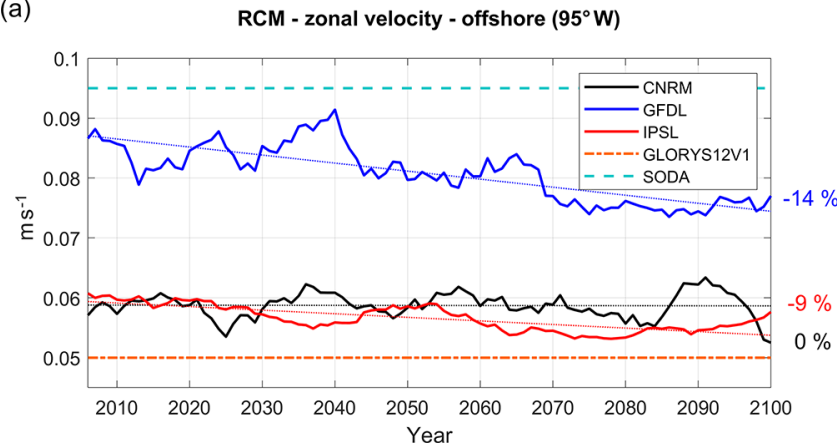

(b)

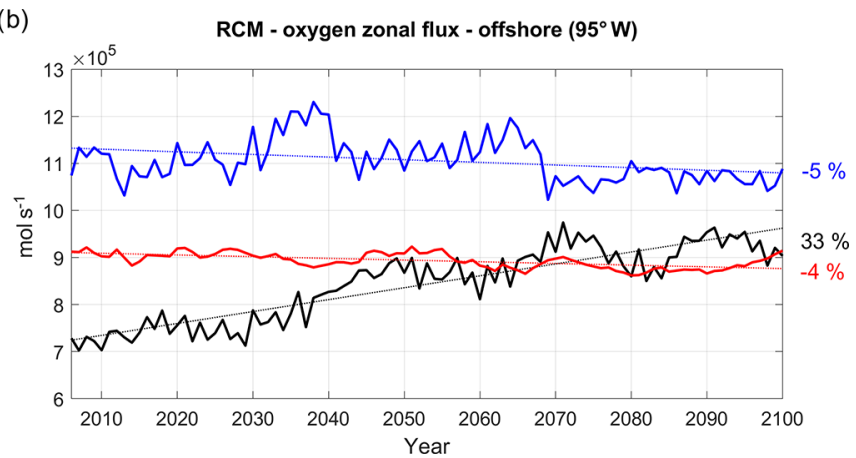

Figure 9. (a) zonal velocity $\left(\mathrm{m} \mathrm{s}^{-1}\right)$ and (b) oxygen zonal flux $\left(\mathrm{mol} \mathrm{s}^{-1}\right)$ in the eastern equatorial Pacific at $95^{\circ} \mathrm{W}$, averaged between $2^{\circ} \mathrm{N}$ and $10^{\circ} \mathrm{S}$ and between 50 and $200 \mathrm{~m}$, for the three RCMs (CNRM in black, GFDL in blue, IPSL in red). The time series are filtered using a 10-year moving average. Mean values from GLORYS12V1 and SODA reanalyses are marked in (a) by a dashed-dotted orange line and a dashed cyan line, respectively.

2019), and the local oxygen consumption due to the respiration of sinking organic matter. The eastward currents in the offshore equatorial region thus play an important role in the ventilation of the OMZ (Stramma et al., 2008; Montes et al., 2014; Cabré et al., 2015; Shigemistu et al., 2017; EspinozaMorriberón et al., 2019). Following Cabré et al. (2015) we first evaluate the ESM eastward subsurface flow (which enters the western boundary of the RCM) at $95^{\circ} \mathrm{W}$ (Fig. 9a). As estimates of mean velocity from ocean reanalysis range between $0.05 \mathrm{~m} \mathrm{~s}^{-1}$ (GLORYS12V1) and $0.09 \mathrm{~m} \mathrm{~s}^{-1}$ (SODA), the uncertainty of the eastward flow is very high. The eastward flow in R-GFDL (in 2005-2010) is 10\% weaker than in SODA. In contrast, the eastward flow is underestimated by $\sim 50 \%$ in R-CNRM and R-IPSL with respect to SODA, probably because of a weak EUC and/or weak SSCCs in these coarse-grid ESMs (Cabré et al., 2015). Over 20062100 , the eastward velocity is stable $(<1 \%$, Fig. 9a, Table 3$)$ in R-CNRM and decreases weakly in R-IPSL $(-9 \%)$ and in R-GFDL (-14\%).

The evolution of the eastward dissolved oxygen (DO) flux at $95^{\circ} \mathrm{W}$ (Fig. 9b) approximately follows that of the mass flux. Due to a strong increase in equatorial DO (not shown), the DO flux uptrend is strong in R-CNRM (33\%, Table 4). This contrasts with the moderate decrease in the DO flux $(\sim-5 \%)$ in the other two simulations. Note that the eastward DO flux is $\sim 25 \%-30 \%$ stronger in R-IPSL than in RCNRM at the beginning of the century. As the eastward flow in the $2-10^{\circ} \mathrm{S}$ equatorial band is stronger in R-IPSL than in R-CNRM (not shown) and the water is more oxygenated in this latitudinal band than within $2^{\circ} \mathrm{S}-2^{\circ} \mathrm{N}$ (e.g., Fig. 4 in Cabré et al., 2015), this results in a stronger DO eastward flux in R-IPSL than in R-CNRM.

We now investigate the nearshore subsurface DO concentration in a box located between 150 and $300 \mathrm{~km}$ offshore, in order to take into account a sufficient number of coarse ESM grid points in the $100-200 \mathrm{~m}$ depth range. The RCM is able to represent the cross-shore structure of the $\mathrm{OMZ}$ with a fair degree of realism (Figs. S1-2). The OMZ bias is weak $\left(<10 \mu \mathrm{mol} \mathrm{L}^{-1}\right.$, Fig. S2) below $\sim 100 \mathrm{~m}$ and increases near $\sim 50-100 \mathrm{~m}$, in the depth range of the oxyclinethermocline. The nearshore DO concentration in the upper part of the OMZ (between 100 and 200 m, Fig. 10a) in 20062015 is slightly higher in R-GFDL $\left(\sim+20 \mu \mathrm{mol} \mathrm{L}^{-1}\right)$ than in the observations $\left(\sim 15-18 \mu \mathrm{mol} \mathrm{L}^{-1}\right)$ and lower in R-IPSL $\left(\sim 10 \mu \mathrm{mol} \mathrm{L}^{-1}\right)$ and R-CNRM $\left(\sim-5 \mu \mathrm{mol} \mathrm{L}^{-1}\right.$; see also Fig. S1).

In contrast, the ESMs strongly overestimate DO in the OMZ (Fig. 10b). The eastward flux at $95^{\circ} \mathrm{W}$ supplies DO to the nearshore $\mathrm{OMZ}$ in greater proportions in R-GFDL than in R-IPSL and R-CNRM (Fig. 9b), partly explaining the discrepancies at the beginning of the century.

The nearshore trends are very different in the three regional simulations. The DO content is virtually unchanged in R-GFDL $(-3 \%$, Table 4$)$ and decreases slowly $(-21 \%)$ in R-IPSL, whereas it increases strongly in R-CNRM $(+483 \%$ $\sim 30 \mu \mathrm{mol} \mathrm{L}^{-1}$ increase). R-GFDL is also marked by a stronger multidecadal variation than the other RCMs. The trends have the same sign as those of the ESMs (Fig. 10b), but DO changes are reduced by half in the RCMs (e.g., $+60 \mu \mathrm{mol} \mathrm{L}^{-1}$ in CNRM versus $\sim+30 \mu \mathrm{mol} \mathrm{L}^{-1}$ in $\mathrm{R}$ $\mathrm{CNRM}, \sim-6 \mu \mathrm{mol} \mathrm{L}-1$ in IPSL versus $\sim-2.5 \mu \mathrm{mol} \mathrm{L}-1$ in R-IPSL).

The depth of the $0.5 \mathrm{mLL}^{-1}\left(22 \mu \mathrm{mol} \mathrm{L}^{-1}\right)$ DO isosurface (hereafter named "oxycline") is often used as a proxy for the OMZ upper limit (e.g., Espinoza-Morriberón et al., 2019), characterizing the vertical extent of the habitat of many living species of the coastal ecosystem (Bertrand et al., 2010, 2014). As R-CNRM oxycline is quite deep (Fig. S2), we averaged its values over a wider coastal box $(0-200 \mathrm{~km})$ in Fig. 10c. The oxycline at the beginning of the century is well positioned in R-GFDL and slightly shallower than the observed oxycline in R-IPSL and R-CNRM (Fig. 10c). Between 2006 and 2100, the oxycline shoals slightly (less than $10 \mathrm{~m}$ ) in R-GFDL and R-IPSL, whereas it deepens by more 
(a)

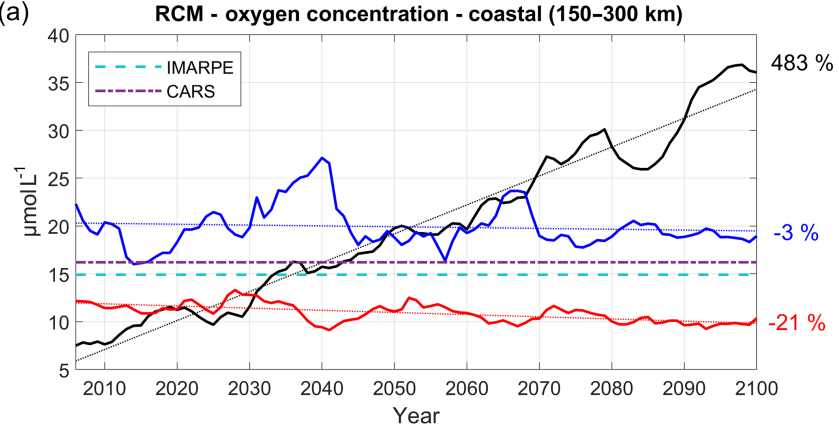

(b)

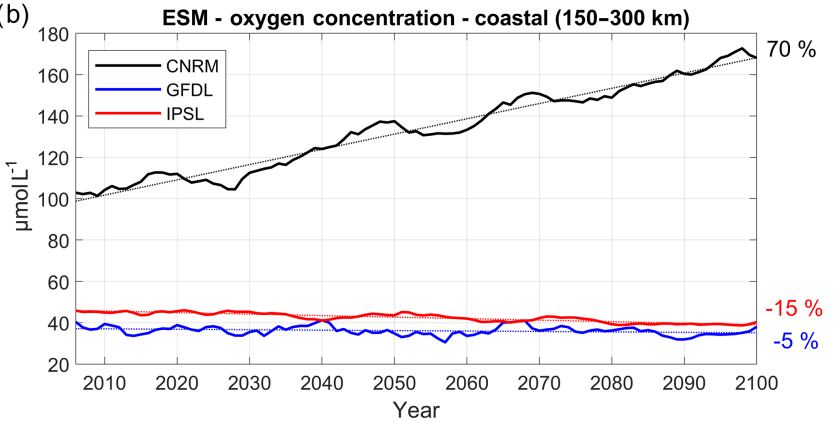

(c)

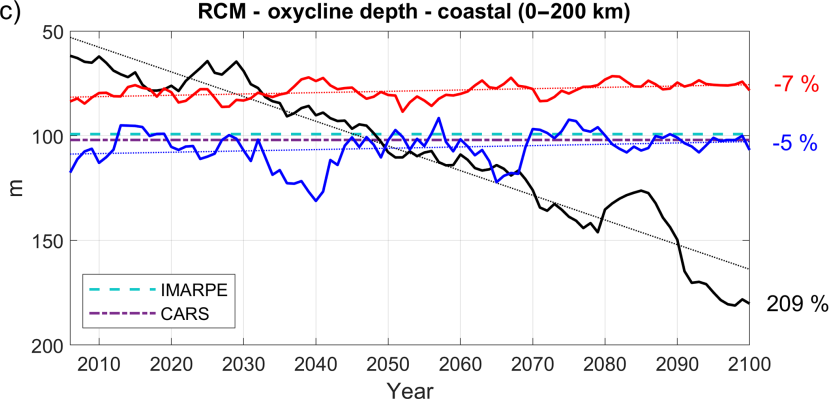

Figure 10. Oxygen concentration $\left(\mu \mathrm{mol} \mathrm{L}^{-1}\right)$ averaged between 100 and $200 \mathrm{~m}$ depth in a coastal box located between 150 and $300 \mathrm{~km}$ from the coast for (a) RCM and (b) ESM; (c) depth of the oxycline $(0.5-22 \mu \mathrm{mol} \mathrm{L}-1)$ isosurface averaged in a $200 \mathrm{~km}$ wide coastal box for the three RCMs (CNRM in black, GFDL in blue, IPSL in red). The time series are filtered using a 10-year moving average. IMARPE (dashed cyan line) and CARS (dashed-dotted purple line) climatological values are also shown.

than $100 \mathrm{~m}$ in R-CNRM. Similar trends are found for the "upper oxycline" defined by the $1 \mathrm{mLL}^{-1}$ isoline (not shown; see Table 4).

\subsubsection{Nitrate trends}

We now investigate the evolution of subsurface nitrate concentrations at $95^{\circ} \mathrm{W}$, the western boundary of the RCM (see red line in Fig. 2b). A decrease is found in all simulations. This is illustrated by the shoaling of the $21 \mu \mathrm{mol} \mathrm{L}^{-1} \mathrm{ni}$ trate iso-surface (Fig. 11a). The downtrends vary between strong (78\% in R-CNRM) and moderate deepening (24\% in R-IPSL and $26 \%$ in R-GFDL, Table 4). Nitrate depletion was also found in the IPSL CMIP3 $4 \times \mathrm{CO}_{2}$ scenario
(Brochier et al., 2013). It is likely caused by a reduced nutrient delivery from the deep ocean to the upper layers of the ocean associated with enhanced thermal stratification, reduced vertical mixing, and overall slowdown of the ocean circulation (e.g., Frölicher et al., 2010). Due to the stronger eastward flow in R-GFLD (Fig. 9a), the associated nitrate eastward flux is $\sim 50 \%$ stronger than in R-IPSL and R-CNRM (Fig. 11b). The fluxes decrease in all simulations $(-27 \%$ in R-CNRM, $-20 \%$ in R-IPSL, $-18 \%$ in R-GFDL, Table 4, Fig. 11b).

Following Espinoza-Morriberón et al. (2017), the depth of the $21 \mu \mathrm{mol} \mathrm{L}^{-1}$ nitrate iso-surface (hereafter D21) in the coastal region is chosen as a proxy of the nearshore nitracline depth (Fig. 11c). In spite of the offshore nitracline deepening (Fig. 11a) and decreasing nitrate flux (Fig. 11b), the nearshore nitracline shoals in R-GFDL ( $-25 \%)$. In contrast, it deepens in R-IPSL $(+32 \%)$ and in R-CNRM $(+82 \%)$. This shows that the equatorial forcing is not always the main forcing of the evolution of the nearshore nitracline depth: whereas it seems to drive nitrate depletion in R-CNRM and R-IPSL, the maintained coastal upwelling in R-GFDL (Fig. 5a) may partly compensate for this effect. It is also notable that the nitracline may shoal even though coastal upwelling does not increase (e.g., in R-GFDL, Fig. 5a). This points to potential changes in nitrate vertical distribution, possibly due to a reduction of nitrate assimilation driven by biomass variations (see Sect. 3.3). The ESM and RCM nearshore nitracline trends are consistent for CNRM and IPSL: nitracline deepens by $97 \%$ (34\%) in CNRM (IPSL) and by $82 \%$ (32\%) in R-CNRM (R-IPSL). In contrast, nitracline shoaling is strong in R-GFDL $(-25 \%)$ and negligible in GFDL $(+2 \%)$. However, note that D21 is too shallow in RCMs ( 20-35 m over 2006-2015) with respect to observations $(\sim 100 \mathrm{~m}$ in CARS) due to an overly high nitrate concentration in subsurface layers (figure not shown). This bias was also found in previous ROMS-PISCES regional simulations of the NHCS (e.g., see also Fig. 3 in EspinozaMorriberón et al., 2017) possibly due to a lack of denitritification.

\subsubsection{Chlorophyll and primary productivity annual variations}

Regional downscaling has a strong impact on the nearshore planktonic biomass. Chlorophyll is used in the following as a proxy of total phytoplankton biomass. The surface chlorophyll concentration at the beginning of the century (Fig. 12a) agrees relatively well with MODIS mean chlorophyll $(\sim$ $\left.4.25 \mathrm{mg} \mathrm{Chl} \mathrm{m}^{-3}\right)$ in R-IPSL $\left(\sim 4.2 \mathrm{mg} \mathrm{Chl} \mathrm{m}^{-3}\right)$ and RGFDL $\left(\sim 4.5 \mathrm{mg} \mathrm{Chl} \mathrm{m}^{-3}\right)$ whereas it is $\sim 30 \%$ higher in R-CNRM $\left(\sim 5.5 \mathrm{mg} \mathrm{Chl} \mathrm{m}^{-3}\right)$. Note that MODIS and SeaWiFS satellite observations differ by $\sim 1 \mathrm{mg} \mathrm{Chl} \mathrm{m}^{-3}$ due to different algorithms (O'Reilly et al., 1998; Letelier and Abbott, 1996) and different time periods (see Sect. 2.6). Moderate uptrends are found in R-GFDL $(+12 \%)$ and R-IPSL 
(a)

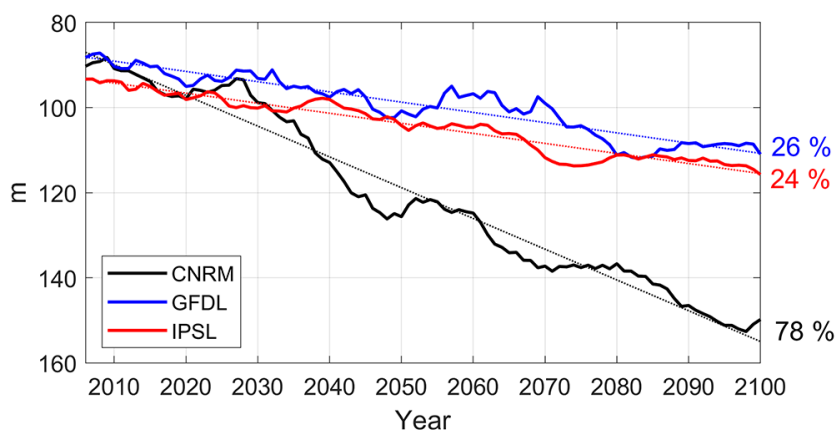

(c)

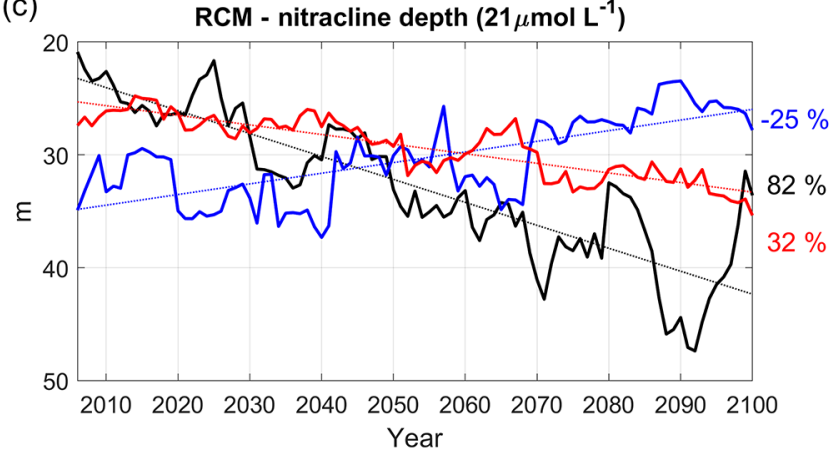

(b)

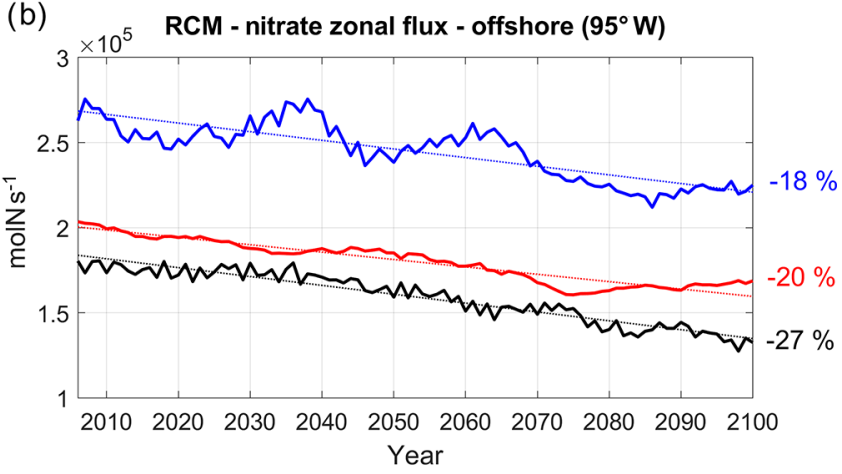

(d)

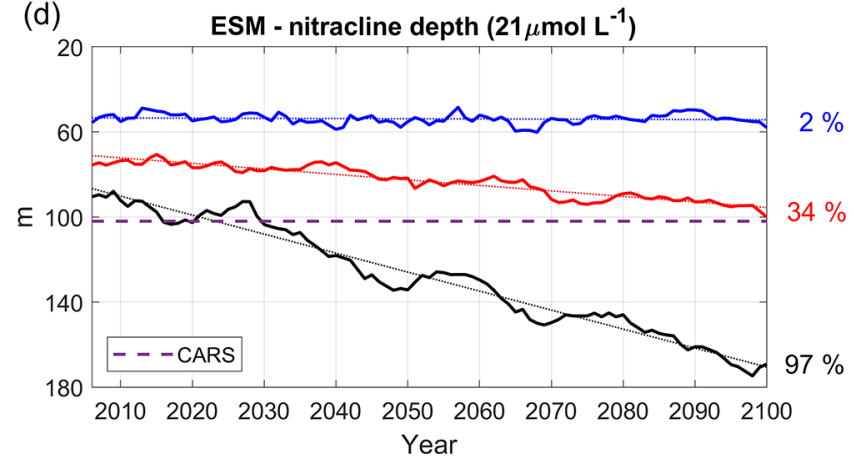

Figure 11. (a) Nitracline depth (i.e., depth of the nitrate $21 \mu \mathrm{mol} \mathrm{L} \mathrm{L}^{-1}$ isosurface) at $95^{\circ} \mathrm{W}$ (averaged between $2^{\circ} \mathrm{N}$ and $10^{\circ} \mathrm{S}$ ), (b) eastward nitrate flux $\left(\mathrm{mol} \mathrm{s}^{-1}\right.$ ) at $95^{\circ} \mathrm{W}$ (averaged between $2^{\circ} \mathrm{N}$ and $10^{\circ} \mathrm{S}, 50-200 \mathrm{~m}$ depth), and (c) nitracline depth (i.e., depth of the nitrate $21 \mu \mathrm{mol} \mathrm{L}{ }^{-1}$ isosurface) averaged in a $100 \mathrm{~km}$ wide coastal box, for the three RCMs (CNRM in black, GFDL in blue, IPSL in red) and (d) for the ESMs. The time series are filtered using a 10-year moving average. CARS (dashed purple line) climatological values are shown in (d).

$(+17 \%$, Table 5). The latter seems at odds with the weak nitracline deepening $(<10 \mathrm{~m}$ between 2006 and 2100) in RIPSL (Fig. 11c). Strong multidecadal variability with almost no trend $(2 \%)$ is found in R-CNRM, in spite of the marked nutricline deepening $(\sim 20 \mathrm{~m}$, Fig. 11c).

RCMs are able to correct the ESM inability to represent nearshore surface chlorophyll concentration (Fig. 12b). Indeed, ESM surface chlorophyll ranges between $0.6-0.7 \mathrm{mg} \mathrm{Chl} \mathrm{m}^{-3}$ (GFDL) and $\sim 0.01-0.1 \mathrm{mg} \mathrm{Chl} \mathrm{m}^{-3}$ (CNRM), almost an order of magnitude smaller than observed values. The ESM trends display very contrasted patterns (Fig. 12b). Surface chlorophyll concentration decreases in all cases, with negative trends between $-11 \%$ and $-104 \%$, a behavior not simulated in the RCMs.

The total chlorophyll content, depth-integrated over 0$500 \mathrm{~m}$ (which includes the euphotic layer) (Fig. 12c), displays weak uptrends in R-IPSL $(+2 \%$, Table 5$)$ and R-GFDL $(+3 \%)$ and a moderate decrease in R-CNRM $(-5 \%)$. Note also the very marked multidecadal variability in R-CNRM. In contrast, weak downtrends $(-3 \%)$ are found in two of the ESMs (IPSL and GFDL, Fig. 12d). Note that the R-CNRM downtrend $(-5 \%)$ is weaker $(-8 \%)$ with respect to CNRM $(-32 \%)$.
The different evolution of the RCM surface and total chlorophyll content implies that the vertical distribution of phytoplankton biomass is modified in the long term. The vertical and cross-shore structure of seasonal chlorophyll trends indicates that both R-GFDL and R-IPSL simulate a chlorophyll increase in the mixed layer near the coast, and a decrease below (Fig. 13a-c). Interestingly, this suggests that total biomass changes cannot be monitored using satellite measurements, as the subsurface plankton depletion cannot be observed. The seasonal trends in R-GFDL and R-IPSL are consistent with a shoaling of the mixed layer (Fig. 7), which reduces light limitation of phytoplankton growth (e.g., Echevin et al., 2008; Espinoza-Morriberón et al., 2017) and increases surface primary productivity in summer and winter. In contrast, the R-CNRM trend in the mixed layer is negative in summer. This is likely caused by the strong deepening of the nitracline in R-CNRM (Fig. 11c) and the seasonality of the wind-driven upwelling. As the upward flow is weaker in summer, the upwelling of less-rich waters into the mixed layer may trigger a nutrient limitation of phytoplankton growth. On the other hand, as the upward flow remains strong during winter, nutrient limitation does not occur. Light limitation of phytoplankton growth decreases because of the shoaling of the mixed layer, enhancing 
(a)

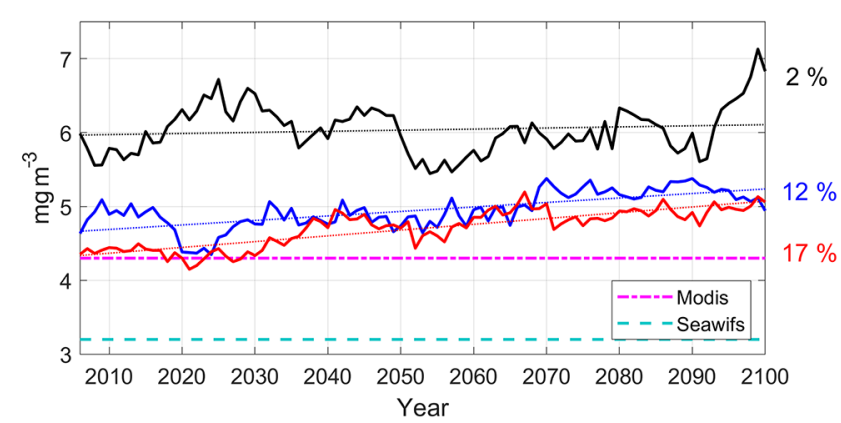

(c)

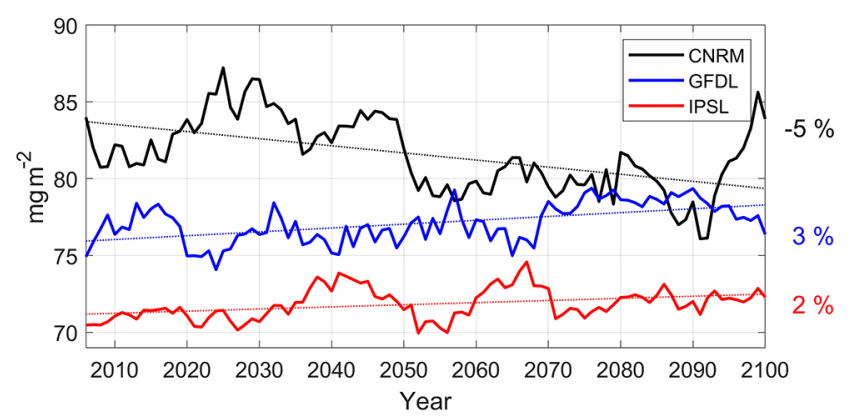

(b)

ESM - surface layer biomass $(0-5 \mathrm{~m})$

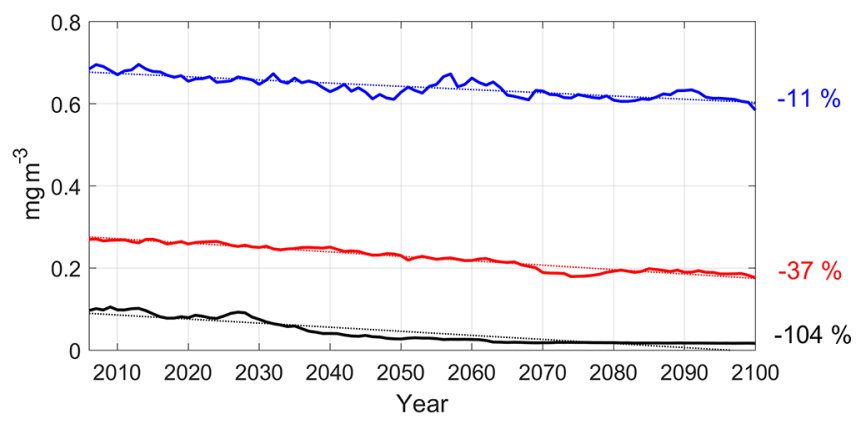

(d)

ESM - total biomass $(0-500 \mathrm{~m})$

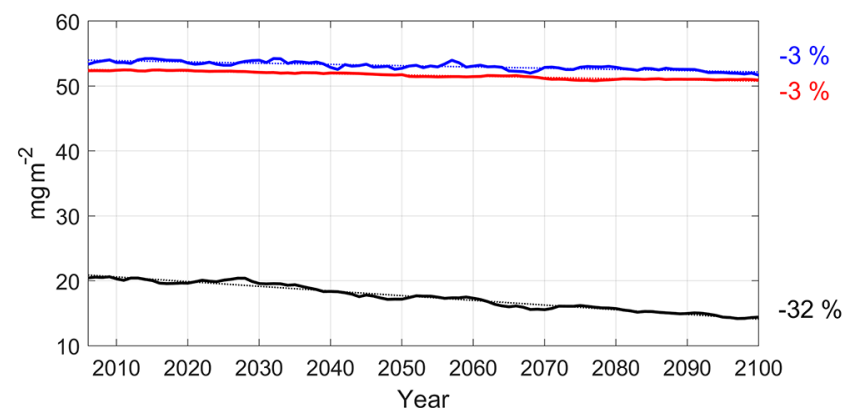

Figure 12. Surface chlorophyll (0-5 m, $\left.\mathrm{mg} \mathrm{Chl} \mathrm{m}^{-3}\right)$ from (a) RCMs and (b) ESMs; depth-averaged chlorophyll concentration (0-50 m, $\mathrm{mg} \mathrm{Chl} \mathrm{m}{ }^{-2}$ ) from (c) RCMs and (d) ESMs. Color code: CNRM in black, GFDL in blue, IPSL in red. The time series are filtered using a 10-year moving average. Thin dotted colored lines indicate the linear trends. All variables are averaged in a coastal box (see Fig. 2a). Dashed cyan and dashed-dotted magenta lines in (a) mark the mean surface chlorophyll from SeaWiFS (1997-2010) and MODIS (2002-2015), respectively.

phytoplankton growth (as in the two other RCMs). Moreover, visual correlation between decadal variability of the chlorophyll content and nitracline depth in R-CNRM (e.g., the oscillations in 2070-2100 in Figs. 11c and 12c) also suggests that nitrate limitation of phytoplankton growth may play a role.

To further investigate the drivers of the surface chlorophyll trends, RCM and ESM primary productivity (PP) trends are shown in Fig. 14. RCM PP surface trends are weak (between $-2 \%$ and $+7 \%$ ). In particular, the weak trend in RIPSL $(-2 \%)$ is at odds with the surface chlorophyll increase $(+17 \%$, Fig. 12a). In all RCMs, PP is strongly impacted by decadal variability as a consequence of upwelling (Fig. 5a) and nitracline depth variability (Fig. 11c). These surface trends contrast with the more pronounced ESM PP trends, in particular for IPSL $(-25 \%)$ and CNRM $(-113 \%)$. However, one may question the meaning of the ESM PP trends associated with very weak (an unrealistic) ESM chlorophyll concentrations (Fig. 12b, d). The RCM depth-integrated PP trends are consistent with those of surface PP but differ from the ESMs, especially for R-CNRM (-7\%) and CNRM $(-66 \%)$.

Overall, the contrasted trends found in the RCMs and ESMs, even when a similar biogeochemical model is used (e.g., PISCES in IPSL and CNRM), illustrate the necessity to regionally downscale ESM variability to reduce systematic bias and better represent local processes impacting on productivity.

\subsubsection{Zooplankton biomass variations}

The two zooplankton groups represented by RCMs are aggregated in a single group to allow a comparison with the ESMs. In contrast with surface phytoplankton, the order of magnitude of surface zooplankton biomass is comparable in ESMs and RCMs, with the exception of CNRM in which zooplankton concentrations are very weak. In addition, RCM surface zooplankton also displays a different evolution than RCM phytoplankton. First, multidecadal variability is quite strong and trends are weak. Zooplankton slightly accumulates in R-GFDL (+4\%, Fig. 15a, Table 5), in line with phytoplankton $(+12 \%$, Fig. 12a), suggesting the possibility of a grazing increase. In contrast, surface zooplankton displays no trend in R-IPSL in spite of a marked surface phytoplankton increase $(+17 \%)$. These weak surface zooplankton trends contrast with the stronger ESM downtrends (from $-15 \%$ (GFDL) to $-98 \%$ (CNRM), Fig. 15b).

Depth-integrated zooplankton biomass decreases moderately in all RCMs, from $-5 \%$ (R-GFDL) to $-15 \%$ (R-IPSL) (Fig. 15c). The GFDL and IPSL depth-integrated zooplank- 


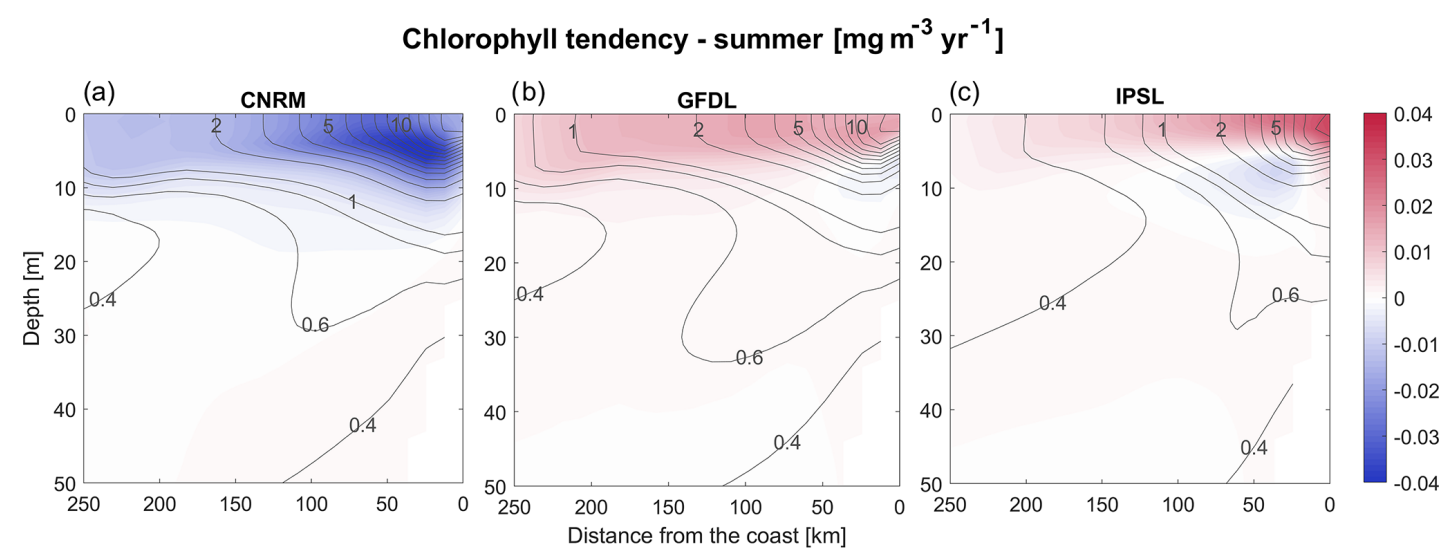

Chlorophyll tendency - winter $\left[\mathrm{mg} \mathrm{m}^{-3} \mathrm{yr}^{-1}\right]$
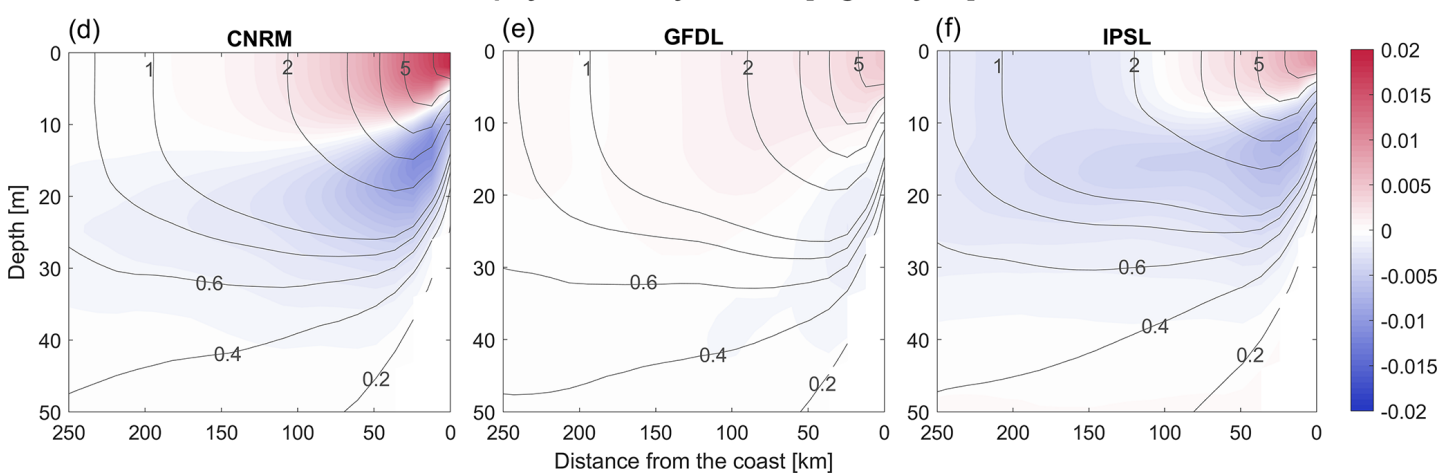

Figure 13. (a-c) Austral summer and (d-f) winter vertical sections of the RCM chlorophyll linear trends $\left(\mathrm{mg} \mathrm{m}^{-3} \mathrm{yr}^{-1}\right)$. The vertical crossshore section corresponds to an alongshore average of cross-shore sections between 7 and $13^{\circ} \mathrm{S}$. Contours represent the mean control values (2006-2015).

ton downtrends are relatively close to the RCM downtrends. CNRM stands out as atypical with a decrease in half of its zooplankton biomass, while the decrease in R-CNRM is moderate $(-11 \%)$. The spatial structure of the trends varies significantly over the vertical and in the cross-shore directions (Fig. 16a-c). The accumulation of zooplankton in RIPSL and R-CNRM near the coast is consistent with a reduction of the offshore advection due to Ekman transport (Fig. 5c). As for chlorophyll (Fig. 13), the zooplankton decrease below $10 \mathrm{~m}$ depth suggests that monitoring of zooplankton must be carried out in the surface layer and below to measure long-term trends.

\section{Summary and discussion}

\subsection{Summary of the main results}

The dynamical downscaling of the ocean circulation and ecosystem functioning for three ESMs is performed in the NHCS for the strongly warming, so-called worst-case RCP8.5 climate scenario. The RCM simulations all show an intense warming of the surface layer within $100 \mathrm{~km}$ from the Peruvian coasts, reaching between +2 and $+4.5^{\circ} \mathrm{C}$ in
2100. We can speculate that the nearshore surface warming is closely associated with a subsurface warming in the near-equatorial region $\left(95^{\circ} \mathrm{W}, 2^{\circ} \mathrm{N}-10^{\circ} \mathrm{S}\right)$ which propagates into the NHCS. The coastal warming is weakest when the wind-driven upwelling is maintained (e.g., in R-GFDL) and strongest when it is reduced (e.g., in R-IPSL and R-CNRM; see also Echevin et al., 2012; Oerder et al., 2015). The coastal warming found in the RCMs is close to that found in the ESMs, but surface and subsurface temperature mean biases (for the period 2006-2015) are greatly reduced in the RCMs.

Biogeochemical trends from the RCMs and ESMs are compared. Two of the three RCMs display a weak decrease in the near-equatorial $\left(95^{\circ} \mathrm{W}, 2^{\circ} \mathrm{N}-10^{\circ} \mathrm{S}\right)$ eastward oxygen flux into the NHCS, associated with a moderate slowdown of the eastward equatorial circulation and weak changes in oxygen concentrations in the equatorial region. Consequently, a relatively weak deoxygenation occurs in the nearshore region. This contrasts with the third RCM, in which the nearequatorial region becomes very oxygenated, which triggers a strong oxygenation of the OMZ.

Nutrient supply from the near-equatorial region to the NHCS decreases in all RCMs due to progressive nitrate depletion of equatorial waters and to decreasing eastward flux. This drives a deepening of the nearshore nitracline in two of 
(a)

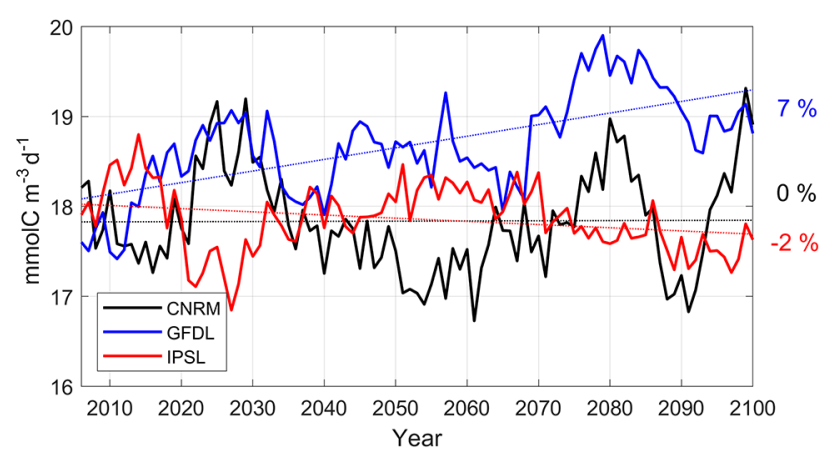

(c)

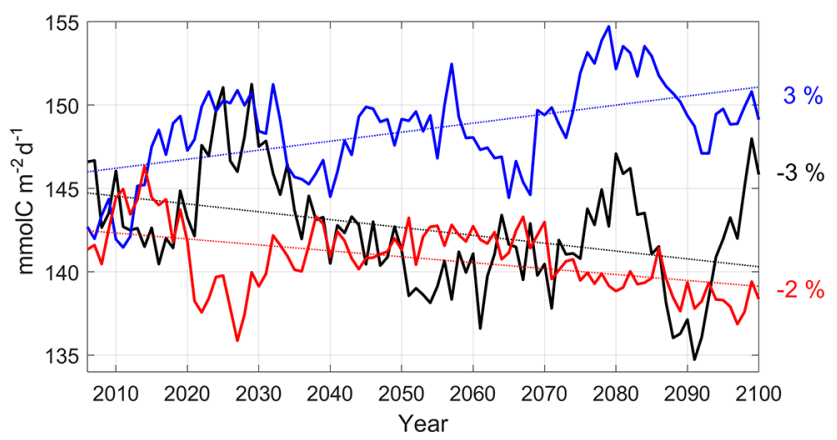

(b)

ESM - surface layer primary production (0-5 m)

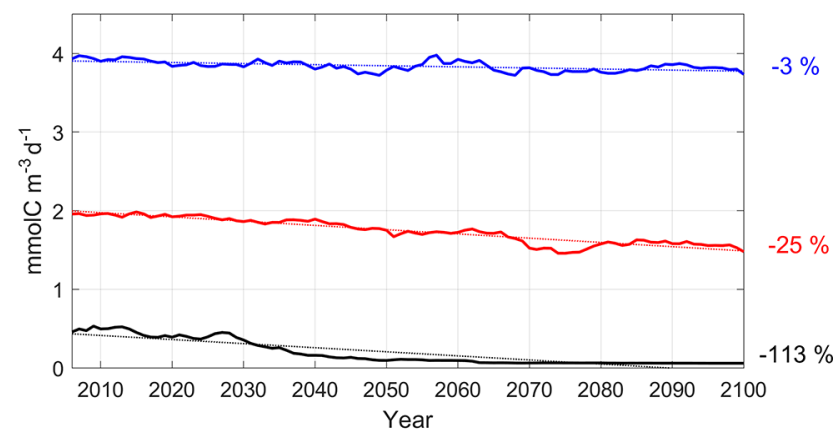

(d)

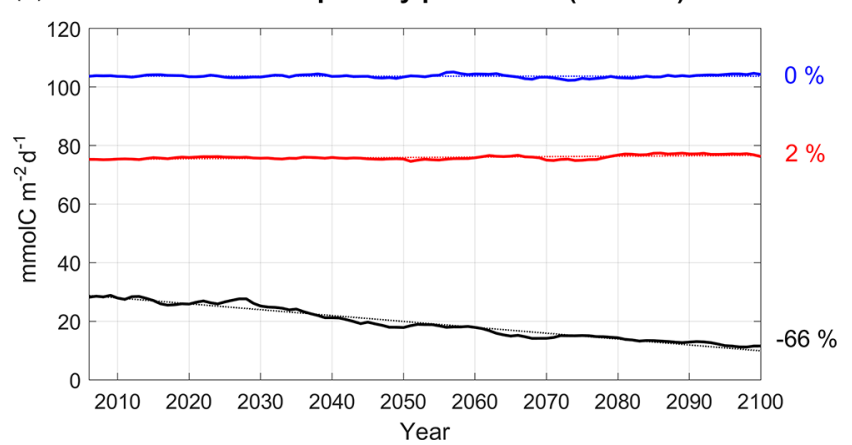

Figure 14. Same as 12 but for primary production $\left(\mathrm{mmol} \mathrm{C} \mathrm{m}^{-3} \mathrm{~d}^{-1}\right)$ for the $0-5 \mathrm{~m}$ surface layer in (a) and (b) and for the depth-integrated values $\left(\mathrm{mmol} \mathrm{C} \mathrm{m}^{-2} \mathrm{~d}^{-1}\right)$ in (c) and (d).

the RCMs and a shoaling in the third RCM in which winddriven coastal upwelling is maintained.

Chlorophyll concentration displays contrasted coastal trends. First, in all RCMs, surface chlorophyll does not decrease, in contrast with ESM downtrends (from $-11 \%$ to $-104 \%)$. Surface chlorophyll increases $(>10 \%)$ in two RCMs, while the total chlorophyll biomass remains stable, indicating an enhanced vertical stratification of phytoplankton in the surface layer in 2100 . Total phytoplanktonic biomass (i.e., integrated over the water column) in the coastal zone remains relatively stable in spite of a slightly decreasing primary productivity driven by a weakening upwelling (in two RCMs) and a deepening nutricline (in two RCMs). This counterintuitive evolution of surface phytoplankton could be partly driven by the reduced offshore transport (related to coastal upwelling) which allows floating organisms to accumulate in the coastal band. Reduced offshore transport may also induce a greater residence time of phytoplankton in the coastal area and hence a stronger prey availability favoring grazing and a larger zooplankton biomass. However, the total zooplankton biomass tends to decrease in all RCMs, which shows that complex nonlinear effects (e.g., temperature and predator-prey relations) drive plankton trends. Note that RCM zooplankton downtrends can be weaker than the ESM downtrends used to drive fish global models (e.g., Tittensor et al., 2018). In the following subsections we discuss in more detail the surface temperature trends, the near- equatorial conditions impacting the NHCS, and the impact of the downscaling on the plankton trends.

\subsection{Selection of the ESMs}

The choice of which ESMs to downscale has been justified on the basis of the comparison of the ESM historical simulations to climatological observations. We are aware that these evaluations do not necessarily correspond to how well a model may capture the response to future climate forcing. The "emergent constraints" approach has been offered as a relevant method for evaluating climate models (e.g., Hall et al. 2019). In this approach, a statistical relation $(F)$ between a present-state variable $(X)$ and a future-state variable $(Y)$ is derived $(Y=F(X))$ using an ESM ensemble, regardless of ESM bias. The relation is then used to derive a future response using the best knowledge of the present state ( $X \_$obs) using $Y=F$ ( $X \_$obs). Following such an approach would have been useful to select the ESM models that fit best with the relation $F$. However, as we are interested in several variables (thermal stratification, upwelling, productivity, OMZ), this would necessitate finding distinct emergent constraints for these variables and thus possibly selecting different ESMs for each constraint, which may be intricate. Such an approach is however promising and should be envisaged in future work. 


\subsection{SST warming}

Enhanced surface heat fluxes and coastal upwelling of offshore-warmed source waters appear to be the main drivers of the nearshore SST evolution. The strongest nearshore warming $\left(+4.5^{\circ} \mathrm{C}\right.$ in 2100$)$ found in R-IPSL likely results from the superposition of four effects: (i) a stronger warming of subsurface waters in the near-equatorial region subsequently transported towards the coastal region, (ii) a reduced cooling due to a decreasing coastal upwelling driven by the wind relaxation, (iii) a stable shortwave flux, and (iv) an increasing downward longwave flux due to the greenhouse effect. Moreover, IPSL-CM5 ranks among the high-sensitivity climate models of CMIP5 due to a large positive low-levelcloud feedback (Brient and Bony, 2013). The weaker surface warming in R-CNRM $\left(+3.5^{\circ} \mathrm{C}\right.$ in 2100$)$ may be mitigated by the weaker insolation. Last, the weakest warming in $\mathrm{R}$ GFDL $\left(+2{ }^{\circ} \mathrm{C}\right.$ in 2100$)$ can be explained by (i) the weakest offshore subsurface temperature anomalies, (ii) the strongest wind-driven coastal upwelling (which brings deeper colder waters to the surface layer), and (iii) the weakest greenhouse forcing. As upwelling-favorable winds are more likely to decrease than to increase in low-latitude EBUSs such as the Peruvian system (Goubanova et al., 2011; Belmadani et al., 2014; Rykacsewski et al., 2015), an upwelling reduction and strong SST warming appear to be the most robust projection. However, a rigorous estimate of the forcing terms in the nearshore heat budget would necessitate the online computation of each term (e.g., Echevin et al., 2018).

Warmer surface waters may have severe consequences on the functioning of the Humboldt current ecosystem as a whole (Doney, 2006; Doney et al., 2012). For instance, in spite of the broad temperature range of small pelagic fish species (e.g., anchovy, sardine, or jack mackerel) habitat (e.g., Gutierrez et al., 2008), the temperature anomalies associated with El Niño events may drive the NHCS into conditions detrimental for pelagic recruitment. Moreover, previous modeling studies based on the RCP8.5 scenario suggest that Peruvian fisheries will be impacted by the poleward migration of exploited species to encounter cooler waters (e.g., Cheung et al., 2018).

\subsection{Near-equatorial eastward flow and OMZ variability}

Eastward EUC and SSCCs are supposed to be strong drivers of $\mathrm{OMZ}$ variability as they transport relatively oxygenated equatorial waters into the OMZ (Cabré et al., 2015; Shigemitsu et al., 2017; Montes et al., 2014; EspinozaMorriberón, 2019; Busecke et al., 2019). This is in line with our results: in all RCMs, the DO trend in the OMZ is consistent with the trend of the offshore eastward DO flux. The EUC is supposed to be mainly forced by the zonal pressure gradient across the equatorial Pacific, associated with the trade winds and the Walker circulation (hereafter
WC; Stommel, 1960). However, most of the CMIP5 climate models fail to reproduce the WC intensification observed in the recent period (1980-2010) (e.g., Kociuba and Power, 2015). Furthermore, the EUC decrease in the eastern equatorial Pacific in GFDL and in IPSL (respectively $-26 \%$ and $-22 \%$ decrease between 2005 and 2100 for the mean velocity between $2^{\circ} \mathrm{N}$ and $2^{\circ} \mathrm{S}, 95^{\circ} \mathrm{W}, 50-200 \mathrm{~m}$ depth, figure not shown) is not consistent with the WC trends reported in Kociuba and Power (2015). Note also that EUC trends vary significantly across the equatorial Pacific (Drenkard and Karnauskas, 2014). EUC dynamics are also likely sensitive to stratification changes in the equatorial thermocline (McCreary, 1981). In brief, to our knowledge, the mechanisms driving long-term EUC variability in the eastern equatorial Pacific remain to be investigated.

Long-term SSCC variability, which contributes to the NHCS trends (e.g., Montes et al., 2014), is also unknown. At basin scale, the primary SSCC (near $4-6^{\circ} \mathrm{S}$ at $90^{\circ} \mathrm{W}$ ) is supposed to be forced partly by trade winds and alongshore winds in the NHCS, by mass exchange between the Pacific basin and the Indian Ocean, and by surface heating in the tropics (McCreary et al., 2002; Furue et al., 2007). The problem is that SSCCs are not resolved in CMIP5 models due to coarse resolution (e.g., see Fig. 4 in Cabré et al., 2015). Last, the observed deoxygenation of water masses in equatorial regions (Stramma et al;, 2008) is underestimated in global models (Oschlies et al., 2018). These uncertainties imply that the ventilation of the NHCS OMZ by the eastward jets may be difficult to project using CMIP5 ESMs.

In order to investigate further the impact of the ESM oxygen conditions on the RCM results, we conducted a series of sensitivity simulations (called R-GCM') using climatological seasonally varying WOA DO concentrations at the regional model open boundaries. Boundary conditions for all the other biogeochemical variables are unchanged with respect to the reference simulations (RCM) (note that we are aware that this simplification introduces inconsistencies in the biogeochemical properties of the water masses, but the results are worth reporting). As expected, the eastward DO flux (Fig. 17a) now follows roughly the mass flux evolution (Fig. 9a) and decreases weakly in each simulation. The huge nearshore DO trend previously found in R-CNRM $(+483 \%$, Fig. 10b) is now much weaker in R-CNRM' $(+36 \%)$ and of a comparable order of magnitude as the other RCM's (Fig. 17b). Furthermore, the marked decrease in the eastward DO flux in R-GFDL' appears to drive a strong nearshore DO decrease. This confirms that strong changes in the nearequatorial eastward ventilation flux impact the OMZ, in line with previous studies (e.g., Shigemitsu et al., 2017). However, ventilation of the OMZ by this mechanism is not the only driver of oxygen variability. Indeed, nearshore deoxygenation can vary (it is slightly more intense in R-IPSL than in R-GFDL, Fig. 10a) in spite of a rather similar decrease in the near-equatorial eastward DO fluxes, possibly owing to different local physical and biogeochemical processes (and 
(a) RCM - surface layer zooplankton biomass (0-5 m)

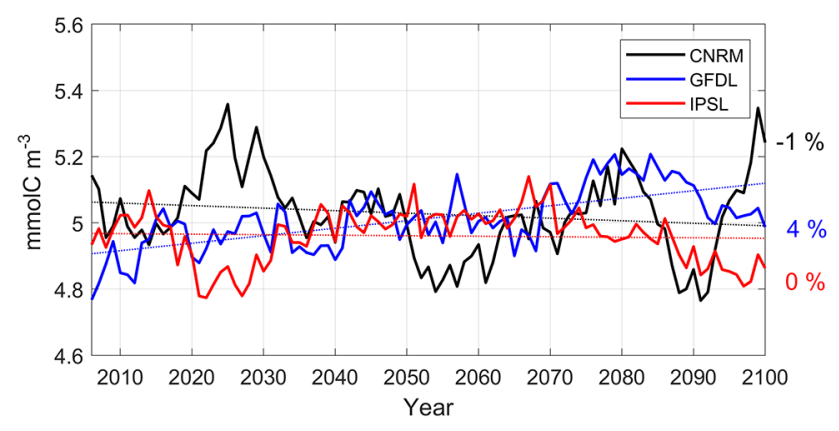

(c)

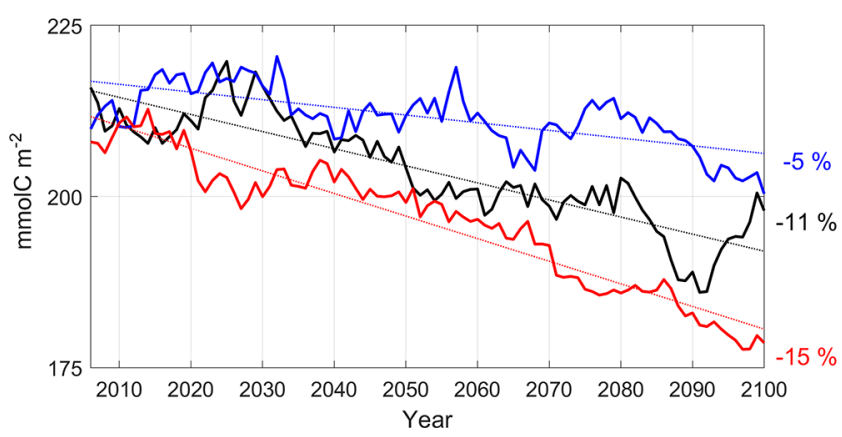

(b)
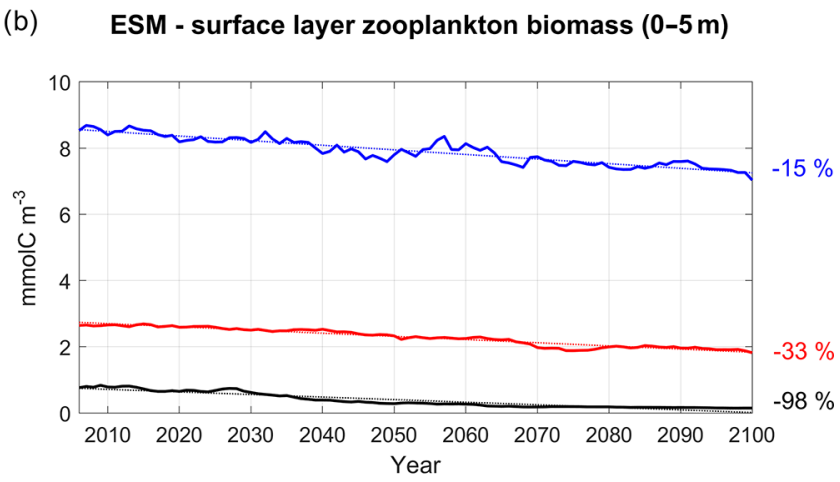

(d)

ESM - total zooplankton biomass $(0-500 \mathrm{~m})$

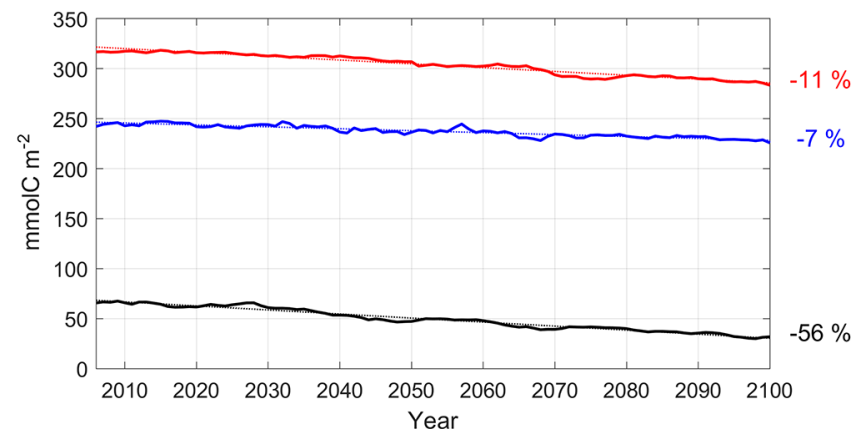

Figure 15. Same as 12 but for zooplankton $\left(\mathrm{mmol} \mathrm{C} \mathrm{m}^{-3}\right)$ for the $0-5 \mathrm{~m}$ surface layer in (a) and (b) and for the depth-integrated values $\left(\mathrm{mmol} \mathrm{C} \mathrm{m}^{-2}\right)$ in $(\mathbf{c})$ and $(\mathbf{d})$.
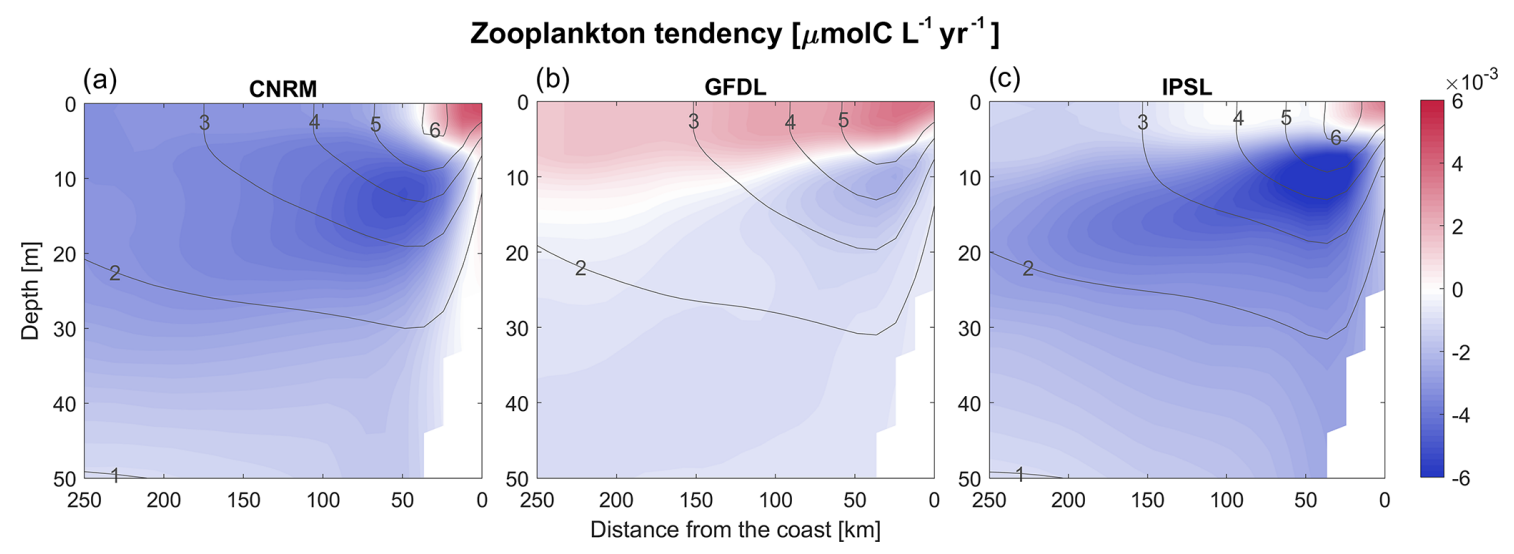

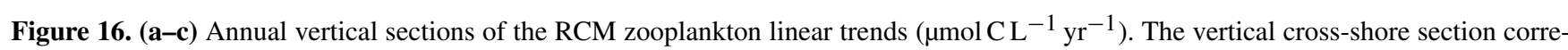
sponds to an alongshore average of cross-shore sections between 7 and $13^{\circ}$ S. Contours represent the mean control values (2006-2015).

thresholds). Computing a rigorous DO budget in the coastal region is needed to investigate in more detail the local processes at stake.

\subsection{Plankton trends}

A stable and, in one case, increasing concentration of chlorophyll is found in the surface layer $(0-5 \mathrm{~m})$, in spite of primary production decrease (e.g., in R-CNRM and R-IPSL, Fig. 14).
Several mechanisms could contribute to partly compensate for the PP decrease.

The shoaling of the mixed layer may constrain phytoplankton vertically and increase surface concentration. The increased temperature in the near-surface layer $(0-50 \mathrm{~m}$ depth) induces a faster growth rate of phytoplankton cells (Eppley, 1972). Furthermore, the decrease in upwelling and offshore export (Fig. 5) may concentrate more biomass in the coastal region and contribute to the phytoplankton persistence in R-IPSL and R-CNRM. However, performing a 

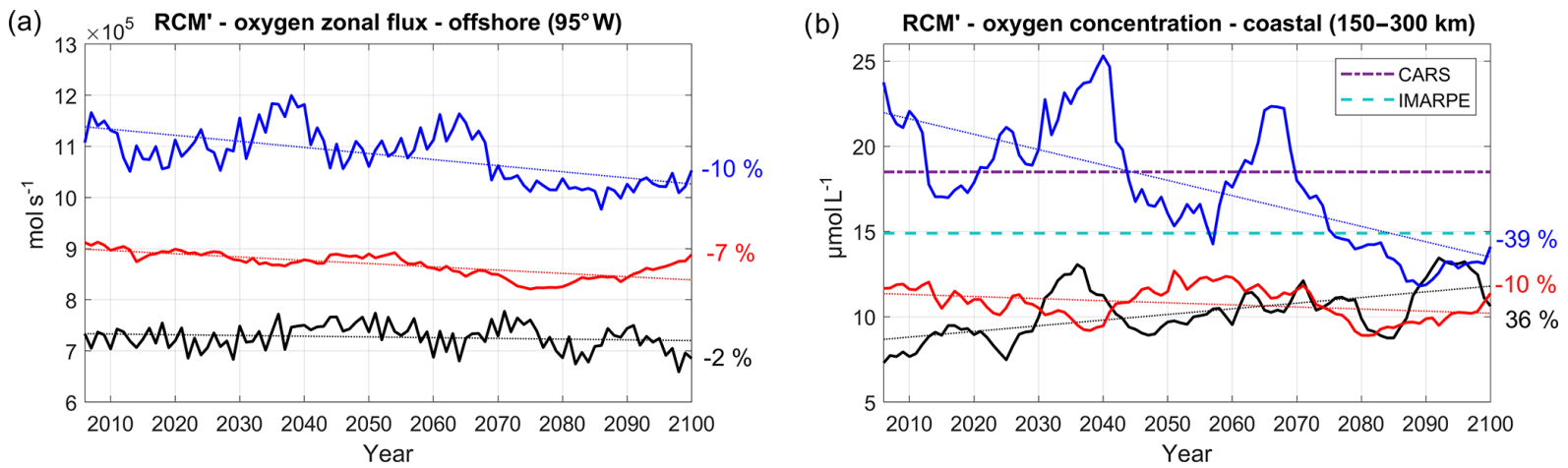

Figure 17. (a) Oxygen flux ( $\mathrm{mol} \mathrm{L}-1$, positive eastward) at $95^{\circ} \mathrm{W}$, averaged between $2^{\circ} \mathrm{N}$ and $10^{\circ} \mathrm{S}$ and between 50 and $200 \mathrm{~m}$, and (b) nearshore subsurface oxygen content (averaged between 100 and $200 \mathrm{~m}$ in a coastal box between 150 and $300 \mathrm{~km}$ from the coast) for the three RCM' simulations (CNRM' in black, GFDL' in blue, IPSL' in red). RCM' simulations are forced by WOA climatological boundary conditions for oxygen. The time series are filtered using a 10-year moving average. CARS (dashed-dotted purple line) and IMARPE (dashed cyan line) climatological values are also shown.

budget of phytoplankton in the model would be needed to precisely estimate the relative contribution of each process, but this is beyond the scope of the present study.

Examination of RCM zooplankton biomass shows weak trends $(0 \%-4 \%)$ in the surface layer and weak downtrends (between $-5 \%$ and $-15 \%$ ) for total biomass (Fig. 15). RIPSL and R-GFDL zooplankton biomass decrease faster than phytoplankton, which corresponds to a trophic attenuation of the transfer of biomass to upper levels. A similar attenuation has been found in regional simulations of the Benguela upwelling system under the IPCC-AR4 A1B scenario (corresponding to the more moderate RCP6.0 scenario; Chust et al., 2014). The RCM zooplankton trends also contrast with the ESM downtrends. These discrepancies can be attributed to local physical processes (transport and mixing associated with the mesoscale) not represented in the ESMs, but also partly to the use of an earlier version of the ecosystem model (PISCES) run with a set of biogeochemical parameters adapted for the NHCS (see Table 1 in Echevin et al., 2014). The stronger total zooplankton biomass downtrends in R-CNRM and R-IPSL suggest a strong impact of the temperature increase, possibly due to the higher zooplankton mortality in a warmer environment. However, the model's microzooplankton and mesozooplankton result from a nonlinear interplay of temperature and predation-mortality effects. Further interpretation of these trends would require dedicated sensitivity experiments and performing a zooplankton budget. This is beyond the scope of the present study, which aims to present an overview of the main low-trophic-level trends.

\section{Conclusions and perspectives}

Regional downscaling of three coarse-grid ESMs is performed in the NHCS over the 21st century so-called worstcase RCP8.5 climate scenario using a high-resolution regional coupled biodynamical model. The downscaling proce- dure allows correction of ESM bias. All regional simulations reproduce an intense warming $\left(2-4.5^{\circ} \mathrm{C}\right)$ of the surface layer within $100 \mathrm{~km}$ from the Peru coasts. The surface warming is strongest when the subsurface equatorial warming is strong and the wind-driven coastal upwelling weakens in the future. Downscaled trends are consistent with those obtained from the ESMs.

The biogeochemical impacts of climate change are more contrasted among RCMs and ESMs. A slowdown of the eastward near-equatorial circulation may reduce the ventilation of the NHCS and induce a nearshore deoxygenation trend. However the long-term variability of oxygen content of equatorial water masses also impacts the nearshore oxygen trends. As observed deoxygenation trends in the eastern equatorial Pacific are not well reproduced by ESMs (Stramma et al., 2008, 2012) and CMIP5 ESM systematic biases are strong in this region (Cabré et al., 2015; Oschlies et al., 2018), these shortcomings limit the predictability of downscaled oxygen trends in the NHCS. One important conclusion of our study is that reducing the biases in oxygen concentration and zonal circulation trends in the eastern equatorial Pacific ocean is crucial to project the future evolution of the NHCS oxygen minimum zone.

Downscaled surface chlorophyll in the coastal region does not decrease, in contrast with the signal projected by the ESMs. In two RCMs, the surface chlorophyll remains high in the coastal region. We can speculate that this happens for two reasons: the enhanced thermal stratification due to the warming may alleviate light limitation and vertical dilution, and the reduction of wind-driven offshore transport may allow plankton to accumulate near the coast. These processes could partly compensate for the reduction of primary productivity due to a deeper nitracline and reduced wind-driven coastal upwelling. Downscaled zooplankton downtrends are also relatively weak (between $-5 \%$ and $-15 \%$ ) but appear to strengthen when the warming is stronger. In all RCMs, 
downscaled plankton trends differ markedly from those simulated by ESMs, in particular in the surface layer $(0-5 \mathrm{~m})$, which illustrates the strong impact of the regional dynamical downscaling. This also underlines the necessity to interpret ESM biomass-based regional projections of fisheries (e.g., FISHMIP; Tittensor et al., 2018) with great caution.

As previous works point to a relaxation of upwellingfavorable wind conditions in the NHCS (e.g., Belmadani et al., 2014), dynamically downscaled wind projections as well as more realistic large-scale dynamical and biogeochemical conditions in the near-equatorial regions are needed to improve the robustness of our results in future studies. Furthermore, many aspects of the regional impact of climate change have not been explored, such as for example interannual variability associated with ENSO in a warmer NHCS or the acidification of coastal waters. These impacts will be addressed in future studies.

Data availability. ESMs data can be downloaded from the World Climate Research Programme: Coupled Model Intercomparison Project 5 (CMIP5), available at: https://esgf-node.llnl.gov/projects/ cmip5/ (last access: 30 June 2020). ROMS_AGRIF regional model code and ROMSTOOLS preprocessing tools can be downloaded on ROMS-AGRIF project, available at: http://www.crocoocean.org/ download/roms_agrif-project/ (last access: 30 June 2020). GLORYS12V1 model output can be downloaded from the Copernicus Marine Service at https://marine.copernicus.eu/ (last access: 30 June 2020). SODA model output can be downloaded from the Asia-Pacific Data-Research Center at the International Pacific Research Center at http://apdrc.soest.hawaii.edu/data/data.php/ (last access: 30 June 2020). CARS2009 climatology can be downloaded from the Asia-Pacific Data-Research Center at the International Pacific Research Center at http://apdrc.soest.hawaii.edu/ datadoc/cars2009.php/ (last access: 30 June 2020). Access to Instituto del Mar del Peru (IMARPE) regional climatologies is available at IMARPE formulario descarga de datos at http://www.imarpe. gob.pe/imarpe/servicios/climatologias/ (last access: 30 June 2020). AVHRR Seas surface Temperature data can be obtained from the National Oceanic and Atmospheric Administration (NOAA) National Centers for Environmental Information at https://www.ncdc. noaa.gov/oisst/ (last access: 30 June 2020). SeaWiFS and MODIS surface chlorophyll data can be downloaded from NASA Ocean Color Data portal at https://oceandata.sci.gsfc.nasa.gov/ (last access: 30 June 2020). Data used in this study can be obtained directly by contacting the authors.

Supplement. The supplement related to this article is available online at: https://doi.org/10.5194/bg-17-3317-2020-supplement.

Author contributions. VE and FC co-designed the study, participated in the analysis of the simulations and wrote the paper. MG processed the ESM data, performed the RCM simulations, produced the figures, and participated in the analysis of the simulations and the writing of the paper. DE-M and JT participated in the analysis and writing of the paper. DG co-designed the study and participated in the writing of the paper. OA provided expertise on the biogeochemical model.

Competing interests. The authors declare that they have no conflict of interest.

Acknowledgements. Regional simulations were performed on the Ada and Jean Zay supercomputers from IDRIS (Institut du Développement et des Ressources en Informatique) during DARI projects nos. A0050101140 and A0060101140, and on the IMARPE cluster. Jorge Ramos is acknowledged for administrating the IMARPE cluster. Richard Soto is acknowledged for downloading the Earth system model output. We thank Michael Jacox and the anonymous reviewer for their constructive comments on the manuscript.

Financial support. The IRD (Institut de Recherche pour le Développement) and the IRD LMI DISCOH program are acknowledged for funding VE, FC, MG, and OA. The IMARPEPRODUCE-IDB project "Adaptation to climate change of the fishery sector and marine-coastal ecosystem of Perú" (PE-G1001/PET1297) is acknowledged for funding DG, JT, and DE.

Review statement. This paper was edited by Christoph Heinze and reviewed by Michael Jacox and one anonymous referee.

\section{References}

Aumont, O., Ethé, C., Tagliabue, A., Bopp, L., and Gehlen, M.: PISCES-v2: an ocean biogeochemical model for carbon and ecosystem studies, Geosci. Model Dev., 8, 2465-2513, https://doi.org/10.5194/gmd-8-2465-2015, 2015.

Bakun, A.: Global climate change and intensification of coastal ocean upwelling, Science, 247, 198-201, 1990.

Bakun, A., Field, D. B., Redondo-Rodriguez, A., and Weeks, S. J.: Greenhouse gas, upwelling-favorable winds, nad the future of coastal ocean upwelling ecosystems, Glob. Change Biol., 16, 1213-1228, https://doi.org/10.1111/j.1365-2486.2009.02094.x, 2010.

Becker, J. J., Sandwell, D. T., Smith, W. H. F., Braud, J., Binder, B., Depner, J., Fabre, D., Factor, J., Ingalls, S., Kim, S.-H., Ladner, R., Marks, K., Nelson, S., Pharaoh, A., Trimmer, R., Von Rosenberg, J., Wallace, G., and Weatherall, P.: Global Bathymetry and Elevation Data at 30 Arc Seconds Resolution: SRTM30_PLUS, Mar. Geodesy, 32, 355-371, 2009.

Belmadani, A., Echevin, V., Codron, F., Takahashi, K., and Junquas, C.: What dynamics drive future winds scenarios off Peru and Chile?, Clim. Dynam., 43, 1893-1914, https://doi.org/10.1007/s00382-013-2015-2, 2014.

Bertrand, A., Ballon, M., and Chaigneau, A.: Acoustic observation of living organisms reveals the upper limit 
of the oxygen minimum zone, PloS ONE, 5, e10330, https://doi.org/10.1371/journal.pone.0010330, 2010.

Bertrand, A., Chaigneau, A., Peraltilla, S., Ledesma, J., Graco, M., Monetti, F., and Chavez, F. P.: Oxygen: a fundamental property regulating pelagic ecosystem structure in the coastal southeastern tropical Pacific, PloS ONE, 6, e29558, https://doi.org/10.1371/journal.pone.0029558, 2011.

Bertrand, A., Grados, D., Colas, F., Bertrand, S., Capet, X., Chaigneau, A., Vargas, A., Mousseigne, A., and Fablet, R.: Broad impacts of fine-scale dynamics on seascape structure from zooplankton to seabirds, Nat. Commun., 5, 5239, https://doi.org/10.1038/ncomms6239, 2014.

Brient, F. and Bony, S.: Interpretation of the positive low-cloud feedback predicted by a climate model under global warming, Clim. Dynam., 40, 2415-2431, 2013.

Brochier, T., Echevin, V., Tam, J., Chaigneau, A., Goubanova, K., and Bertrand, A.: Climate change scenario experiment predict a future reduction in small pelagic fish recruitment in the Humboldt Current system, Global Change Biol., 19, 1841-1853, https://doi.org/10.1111/gcb.12184, 2013.

Busecke, J. J. M., Resplandy, L., and Dunne, J. P. P.: The Equatorial Undercurrent and the oxygen minimum zone in the Pacific, Geophys. Res. Lett., 46, 2124-2139, 2019.

Cabré, A., Marinov, I., Bernardello, R., and Bianchi, D.: Oxygen minimum zones in the tropical Pacific across CMIP5 models: mean state differences and climate change trends, Biogeosciences, 12, 5429-5454, https://doi.org/10.5194/bg-12-54292015, 2015.

Cambon, G., Goubanova, K., Marchesiello, P., Dewitte, B., and Illig, S.: Assessing the impact of downscaled winds on a regional ocean model simulation of the Humboldt system, Ocean Model., 65, 11-24, https://doi.org/10.1016/j.ocemod.2013.01.007, 2013.

Carton, J. A. and Giese, B. S.: A reanalysis of ocean climate using Simple Ocean Data Assimilation (SODA), Mon. Weather Rev., 136, 2999-3017, https://doi.org/10.1175/2007MWR1978.1, 2008.

Chavez, F., Bertrand, A., Guevara-Carrasco, R., Soler, P., and Csirke J.: The northern Humboldt Current System: Brief history, present status and a view towards the future, Prog. Oceanogr., 79, 95105, https://doi.org/10.1016/j.pocean.2008.10.012, 2008.

Cheung, W. W. L., Bruggeman, J., and Butenschön, J.: Projected changes in global and national potential marine fisheries catch under climate change scenarios in the twenty-first century, in: Impacts of climate change on fisheries and aquaculture: Synthesis of current knowledge, adaptation and mitigation options, Food and Agriculture Organization of United Nation, p. 632018. Chust, G., Allen, J. I., Bopp, L., Schrum, C., Holt, J., Tsiaras, K., Zavatarelli, M., Chifflet, M., Cannaby, H., Dadou, I., Daewel, U., Wakelin, S. L., Machu, E., Pushpadas, D., Butenschon, M., Artioli, Y., Petihakis, G., Smith, C., Garçon, V., Goubanova, K., Le Vu, B., Fach, B. A., Salihoglu, B., Clementi, E., and Irigoien, X.: Biomass changes and trophic amplification of plankton in a warmer ocean, Global Change Biol., 20, 2124 2139, https://doi.org/10.1111/gcb.12562, 2014.

Colas, F., Capet, X., McWilliams, J. C., and Shchepetkin, A.: 19971998 El Niño off Peru: A numerical study, Prog. Oceanogr., 79, 138-155, 2008.

Czeschel, R., Stramma, L., Schwarzkopf, F. U., Giese, B. S., Funk, A., and Karstensen, J.: Middepth circulation of the eastern tropical South Pacific and its link to the oxygen minimum zone, J. Geophys. Res., 116, C01015, https://doi.org/10.1029/2010JC006565, 2011.

Da Silva, A. M., Young, C. C., and Levitus, S.: Atlas of Surface Marine Data 1994, vol. 1, Algorithms and Procedures, Technical Report, Washington, D.C: U.S. Department of Commerce, Vol. 6, 2910-3282, 1994.

de Boyer Montégut, C., Madec, G., Fischer, A. S., Lazar, A., and Iudicone, D.: Mixed layer depth over the global ocean: An examination of profile data and a profilebased climatology, J. Geophys. Res., 109, C12003, https://doi.org/10.1029/2004JC002378, 2004.

Doney, S. C.: Plankton in a warmer world. Nature, 444, 695-696. https://doi.org/10.1038/444695a, 2006.

Doney, S. C., Ruckelshaus, M., Emmett D. J., Barry, J. P., Chan, F., English, C. A., Galindo, H. M., Grebmeier, J. M., Hollowed, A. B., Knowlton, N., Poloniva, J., Rabalais, N. N., Sydeman, W. J., and Talley, L. D.: Climate Change Impacts on Marine Ecosystems, Annu. Rev. Mar. Sci., 4, 11-37, https://doi.org/10.1146/annurev-marine-041911-111611, 2012.

Drenkard, E. J. and Karnauskas, K. B.: Strengthening of the Pacific equatorial undercurrent in the SODA reanalysis: Mechanisms, ocean dynamics, and implications, J. Climate, 27, 2405-2416, 2014.

Echevin, V., Aumont, O., Ledesma, J., and Flores, G.: The seasonal cycle of surface chlorophyll in the Peruvian upwelling system: a model study, Prog. Oceanogr., 79, 167-176, https://doi.org/10.1016/j.pocean.2008.10.026, 2008.

Echevin, V., Colas, F., Chaigneau, A., and Penven, P.: Sensitivity of the Northern Humboldt Current System nearshore modeled circulation to initial and boundary conditions, J. Geophys. Res.Oceans, 116, C07002, https://doi.org/10.1029/2010JC006684, 2011.

Echevin, V., Goubanova, K., Belmadani, A., and Dewitte, B.: Sensitivity of the Humboldt Current system to global warming: a downscaling experiment of the IPSL-CM4 model, Clim. Dynam., 38, 761-774, 2012.

Echevin, V., Albert, A., Lévy, M., Aumont, O., Graco, M., and Garric, G.: Remotely-forced intraseasonal variability of the Northern Humboldt Current System surface chlorophyll using a coupled physical-ecosystem model, Cont. Shelf. Res., 73, 14-30, https://doi.org/10.1016/j.csr.2013.11.015, 2014.

Echevin, V., Colas, F., Espinoza-Morriberón, D., Vasquez, L., Anculle, T., and Gutierrez, D.: Forcings and Evolution of the 2017 Coastal El Niño Off Northern Peru and Ecuador, Front. Mar. Sci., 5, 367, https://doi.org/10.3389/fmars.2018.00367, 2018.

Eppley, R. W.: Temperature and phytoplankton growth in the sea, Fish. Bull, 70, 1063-1085, 1972.

Espinoza-Morriberón, D., Echevin, V., Colas, F., Tam, J., Ledesma, J., Vásquez, L., and Graco, M.: Impacts of El Niño events on the Peruvian upwelling system productivity, J. Geophys. Res.-Oceans, 122, 5423-5444, https://doi.org/10.1002/2016JC012439, 2017.

Espinoza-Morriberón, D., Echevin, V., Colas, F., Tam, J., Gutierrez, D., Graco, M., Ledesma, J., and QuispeCcalluari, C.: Oxygen Variability During ENSO in the Tropical South Eastern Pacific, Front. Mar. Sci., 5, 526, https://doi.org/10.3389/fmars.2018.00526, 2019. 
Espinoza-Morriberón, D.: Variabilité interannuelle et décadale de la productivité et de la zone de minimum d'oxygène dans le système d'upwelling du Pérou, $\mathrm{PhD}$ dissertation, Sorbonne University, Paris, France, p. 209, 2018.

Ferry, N., Parent, L., Garric, G., Bricaud, C., Testut, C-E., Le Galloudec, O., Lellouche, J.-M., Drévillon, M., Greiner, E., Barnier, B., Molines, J.-M., Jourdain, N., Guinehut, S., Cabanes, C., and Zawadzki, L.: GLORYS2V1 global ocean reanalysis of the altimetric era (1992-2009) at meso scale, Mercator Ocean-Quaterly Newsletter, 44, 2012.

Furue, R., McCreary, J. P., Yu, Z., and Wang, D.: The dynamics of the southern Tsuchiya Jet, J. Phys. Oceanogr., 37, 531-553, https://doi.org/10.1175/JPO3024.1, 2007.

Flato, G., Marotzke, J., Abiodun, B., Braconnot, P., Chou, S.C., Collins, W., Cox, P., Driouech, F., Emori, S., Eyring, V., Forest, C., Gleckler, P., Guilyardi, E., Jakob, C., Kattsov, V., Reason, C., and Rummukainen, M.: Evaluation of climate models, Climate Change 2013: The Physical Science Basis, in: Contribution of Working Group I to the Fifth Assessment Report of the Intergovernmental Panel on Climate Change, edited by: Stocker, T. F., Qin, D., Plattner, G.-K., Tignor, M., Allen, S. K., Boschung, J., Nauels, A., Xia, Y., Bex, V., and Midgley, P. M., Cambridge Univ. Press, Cambridge, U.K., and New York, https://doi.org/10.1017/CBO9781107415324.020, 741866, 2013

Franco, A. C., Gruber, N., Frolicher, T. L., and Kropuenske Artman, L.: Contrasting impact of future $\mathrm{CO}_{2}$ emission scenarios on the extent of $\mathrm{CaCO}_{3}$ mineral undersaturation in the Humboldt Current System, J. Geophys. Res.-Oceans, 123, 20182036, https://doi.org/10.1002/2018JC013857, 2018.

Goubanova, K., Echevin, V., Dewitte, B., Codron, F., Takahashi, K., Terray, P., and Vrac, M.: Statistical downscaling of sea-surface wind over the Peru-Chile upwelling region: diagnosing the impact of climate change from the IPSL-CM4 model, Clim. Dynam., 36, 1365-1378, https://doi.org/10.1007/s00382-010-0824$0,2010$.

Grados, C., Chaigneau, A., Echevin, V., and Domínguez, N.: Upper ocean hydrology of the Northern Humboldt Current System at seasonal, interannual and interdecadal scales, Prog. Oceanogr., 165, 123-144, 2018.

Graco, M., Anculle, T., Chaigneau, A., Ledesma, J., Flores, G., Morón, O., Monetti, F., and Gutiérrez, D.: Variabilidad espacial y temporal del oxígeno disuelto y de la ZMO en el sistema de afloramiento frente a Perú, Libro de la Anchoveta 2020 in press, 2020.

Gruber, N., Frenzel, H., Doney, S. C., Marchesiello, P., McWilliams, J. C., Moisan, J. R., Oram, J. J., Plattner, G.-K., and Stolzenbach, K. D.: Eddy-resolving simulation of plankton ecosystem dynamics in the California Current System, Deep-Sea Res. Pt. I, 53, 1483-1516, 2006.

Gutiérrez, D., Bouloubassi, I., Sifeddine, A., Purca, S., Goubanova, K., Graco, M., Field, D., Méjanelle, L., Velazco, F., Lorre, A., Salvatteci, R., Quispe, D., Vargas, G., Dewitte, B., and Ortlieb, L.: Coastal cooling and increased productivity in the main upwelling zone off Peru since the mid-twentieth century, Geophys. Res. Lett., 38, L07603, https://doi.org/10.1029/2010GL046324, 2011.

Gutierrez, M., Ramirez, A., Bertrand, S., Moron, O., and Bertrand, A.: Ecological niches and areas of overlap of the squat lobster "munida" (Pleuroncodes monodon) and anchoveta (Engraulis ringens) off Peru, Prog. Oceanogr., 79, 256-263, 2008.

Hall, A., Cox, P., Huntingford, C., and Klein, S.: Progressing emergent constraints on future climate change, Nat. Clim. Change, 9, 269-278, 2019.

Jacox, M. G., Edwards, C. A., Hazen, E. L., and Bograd, S. J.: Coastal upwelling revisited: Ekman, Bakun, and improved upwelling indices for the U.S. West Coast, J. Geophys. Res.-Oceans, 123, 7332-7350, https://doi.org/10.1029/2018JC014187, 2018.

Karstensen, J., Stramma, L., and Visbeck, M.: Oxygen minimum zones in the eastern tropical Atlantic and Pacific oceans, Prog. Oceanogr., 77, 331-350, 2008.

Kociuba, G. and Power, S. B.: Inability of CMIP5 models to simulate recent strengthening of the Walker circulation: Implications for projections, J. Climate, 28, 20-35, 2015.

Large, W. G., McWilliams, J. C., and Doney, S.: Oceanic vertical mixing: a review and a model with a nonlocal boundary layer parameterization, Rev. Geophys. 32, 363-403, https://doi.org/10.1029/94RG01872, 1994.

Letelier, R. M. and Abbott, M. R.: An analysis of chlorophyll fluorescence algorithms for the Moderate Resolution Imaging Spectrometer (MODIS), Remote Sens. Environ., 58, 215-223, 1996.

L'Heureux, M., Lee, S., and Lyon, B.: Recent multidecadal strengthening of the Walker circulation across the tropical $\mathrm{Pa}-$ cific, Nat. Clim. Change, 3, 571-576, 2013.

Li, Q. and Fox-Kemper, B.: Assessing the Effects of Langmuir Turbulence on the Entrainment Buoyancy Flux in the Ocean Surface Boundary Layer, J. Phys. Oceanogr., 47, 2863-2886, https://doi.org/10.1175/JPO-D-17-0085.1, 2017.

Liu, W. T., Katsaros, K. B., and Businger, J. A.: Bulk parameterization of air-sea exchanges of heat and water vapor including the molecular constraints at the interface, J. Atmos. Sci. 36, 1722-1735, https://doi.org/10.1175/15200469(1979)036<1722:BPOASE>2.0.CO;2, 1979.

Luyten, J. R., Pedlosky, J., and Stommel, H.: The Ventilated Thermocline, J. Phys. Oceanogr., 13, 292-309, https://doi.org/10.1175/15200485(1983)013<0292:TVT>2.0.CO;2, 1983.

McCreary, J. P.: A linear stratified ocean model of the equatorial undercurrent, Philos. T. Roy. Soc. A, 298, 1444, https://doi.org/10.1098/rsta.1981.0002, 1981.

McCreary Jr, J. P., Lu, P., and Yu, Z.: Dynamics of the Pacific subsurface countercurrents, J. Phys. Oceanogr., 32, 2379-2404, 2002.

Mogollón, R. and Calil, P. H.: Counterintuitive effects of global warming-induced wind patterns on primary production in the northern Humboldt current system, Glob. Chang. Biol., 24, 3187-3198, https://doi.org/10.1111/gcb.14171, 2018.

Montes, I., Colas, F., Capet, X., and Schneider, W.: On the pathways of the equatorial subsurface currents in the eastern equatorial Pacific and their contributions to the PeruChile Undercurrent, J. Geophys. Res.-Oceans, 115, C09003, https://doi.org/10.1029/2009JC005710, 2010.

Montes, I., Schneider, W., Colas, F., Blanke, B., and Echevin, V.: Subsurface connections in the eastern tropical Pacific during $\mathrm{La}$ Niña 1999-2001 and El Niño 2002-2003, J. Geophys. Res.Oceans, 116, C12022, https://doi.org/10.1029/2011JC007624 2011. 
Montes, I., Dewitte, B., Gutknecht, E., Paulmier, A., Dadou, I., and Oschlies, A.: High-resolution modeling of the Eastern Tropical Pacific Oxygen Minimum Zone: sensitivity to the tropical oceanic circulation, J. Geophys. Res.-Oceans, 119, 5515-5532, https://doi.org/10.1002/2014JC009858, 2014.

Oerder, V., Colas, F., Echevin, V., Codron, F., Tam, J., and Belmadani, A.: Peru-Chile upwelling dynamics under climate change, J. Geophys. Res.-Oceans, 120, 1152-1172, https://doi.org/10.1002/2014JC010299, 2015.

O'Reilly, J. E., Maritorena, S., Mitchell, B. G., Siegel, D. A., Carder, K. L., Garver, S. A., Kahru, M., and McClain, C.: Ocean color chlorophyll algorithms for SeaWiFS, J. Geophys. Res.Oceans, 103, 24937-24953, https://doi.org/10.1029/98JC02160, 1998.

Oschlies, A., Brandt, P., Stramma, L., and Schmidtko, S.: Drivers and mechanisms of ocean deoxygenation, Nat. Geosci., 11, 467473, https://doi.org/10.1038/s41561-018-0152-2, 2018.

Oyarzún, D. and Brierley, C. M.: The future of coastal upwelling in the Humboldt current from model projections, Clim. Dynam., 52, 599-615, 2019.

Penven, P., Debreu, L., Marchesiello, P., and McWilliams, J. C.: Evaluation and application of the ROMS 1-way embedding procedure to the central California upwelling system, Ocean Model., 12, 157-187, https://doi.org/10.1016/j.ocemod.2005.05.002, 2006.

Penven, P., Echevin, V., Pasapera, J., Colas, F., and Tam, J.: Average circulation, seasonal cycle, and mesoscale dynamics of the Peru Current System:a modeling approach, J. Geophys. Res.-Oceans, 110, C10021, https://doi.org/10.1029/2005JC002945, 2005.

Penven, P., Marchesiello, P., Debreu, L., and Lefèvre, J.: Software tools for pre-and post-processing of oceanic regional simulations, Environ. Model. Softw., 23, 660-662, https://doi.org/10.1016/j.envsoft.2007.07.004, 2008.

Resplandy, L., Lévy, M., Bopp, L., Echevin, V., Pous, S., Sarma, V. V. S. S., and Kumar, D.: Controlling factors of the oxygen balance in the Arabian Sea's OMZ, Biogeosciences, 9, 50955109, https://doi.org/10.5194/bg-9-5095-2012, 2012.

Ridgway, K. R., Dunn, J. R., and Wilkin, J. L.: Ocean interpolation by four-dimensional least squares-Application to the waters around Australia, J. Atmos. Ocean. Tech., 19, 1357-1375, 2002.

Risien, C. and Chelton, D.: A global climatology of surface wind and wind stress fields from eight years of Quikscat scatterometer data, J. Phys. Oceanogr., 38, 2379-2413, https://doi.org/10.1175/2008JPO3881.1, 2008.

Rykaczewski, R. R., Dunne, J. P., Sydeman, W. J., García-Reyes, M., Black, B. A., and Bograd, S. J.: Poleward displacement of coastal upwelling-favorable winds in the ocean's eastern boundary currents through the 21 st century, Geophys. Res. Lett., 42, 6424-6431, https://doi.org/10.1002/2015GL064694, 2015.

Shchepetkin, A. F. and McWilliams, J. C.: Quasi-monotone advection schemes based on explicit locally adaptive dissipation, Mon. Weather Rev., 126, 1541-1580, https://doi.org/10.1175/15200493(1998)126<1541:QMASBO>2.0.CO;2, 1998.
Shchepetkin, A. F. and McWilliams, J. C.: The regional oceanic modeling system (ROMS): a split-explicit, free-surface, topography-following-coordinate oceanic model, Ocean Model., 9, 347-404, https://doi.org/10.1016/j.ocemod.2004, 2005.

Shchepetkin, A. F. and McWilliams, J. C.: Correction and commentary for "Ocean forecasting in terrain-following coordinates: formulation and skill assessment of the regional ocean modeling system" by Haidvogel et al., Comp. J. Phys., 227, 3595-3624, 2009.

Shigemitsu, M., Yamamoto, A., Oka, A., and Yamanaka, Y.: One possible uncertainty in CMIP5 projections of low-oxygen water volume in the Eastern Tropical Pacific, Global Biogeochem. Cy., 31, 804-820, https://doi.org/10.1002/2016GB005447, 2017.

Smith, W. H. and Sandwell, D. T.: Global sea floor topography from satellite altimetry and ship depth soundings, Science, 277, 19561962, https://doi.org/10.1126/science.277.5334.1956, 1997.

Stommel, H.: Wind-drift near the equator, Deep-Sea Res., 6, 298 302, 1960.

Stramma, L., Johnson, G. C., Sprintall, J., and Mohrholz, V.: Expanding Oxygen-Minimum Zones in the tropical oceans, Science, 320, 655-658, https://doi.org/10.1126/science.1153847, 2008.

Stramma, L., Schmidtko, S., Levin, L. A., and Johnson, G. C.: Ocean oxygen minima expansions and their biological impacts, Deep-Sea Res. Pt. 1, 57, 587-595, 2010.

Thomsen, S., Kanzow, T., Colas, F., Echevin, V., Krahmann, G., and Engel, A.: Do submesoscale frontal processes ventilate the oxygen minimum zone off Peru?, Geophys. Res. Lett., 43, 81338142, https://doi.org/10.1002/2016GL070548, 2016.

Tittensor, D. P., Eddy, T. D., Lotze, H. K., Galbraith, E. D., Cheung, W., Barange, M., Blanchard, J. L., Bopp, L., Bryndum-Buchholz, A., Büchner, M., Bulman, C., Carozza, D. A., Christensen, V., Coll, M., Dunne, J. P., Fernandes, J. A., Fulton, E. A., Hobday, A. J., Huber, V., Jennings, S., Jones, M., Lehodey, P., Link, J. S., Mackinson, S., Maury, O., Niiranen, S., Oliveros-Ramos, R., Roy, T., Schewe, J., Shin, Y.-J., Silva, T., Stock, C. A., Steenbeek, J., Underwood, P. J., Volkholz, J., Watson, J. R., and Walker, N. D.: A protocol for the intercomparison of marine fishery and ecosystem models: Fish-MIP v1.0, Geosci. Model Dev., 11, 1421-1442, https://doi.org/10.5194/gmd-11-1421-2018, 2018.

Tokinaga, H. and Xie, S. P.: Wave-and anemometer-based sea surface wind (WASWind) for climate change analysis, J. Climate, 24, 267-285, 2011.

van Vuuren, D. P., Edmonds, J., Kainuma, M., Riahi, K., Thomson, A., Hibbard, K., Hurtt, G. C., Kram, T., Krey, V., Lamarque, J.F., Masui, T., Meinshausen, M., Nakicenovic, N., Smith, S. J., and Rose, S. K.: The representative concentration pathways: an overview, Clim. Change, 109, 5, https://doi.org/10.1007/s10584011-0148-z, 2011

Wang, D., Gouhier, T. C., Menge, B. A., and Ganguly, A. R.: Intensification and spatial homogenization of coastal upwelling under climate change, Nature, 518, 390-394, https://doi.org/10.1038/nature14235, 2015. 